\title{
Dynamic Response Characteristics and Failure Mechanism of Coal Slopes with Weak Intercalated Layers under Blasting Loads
}

\author{
Guang-wei Liu $\mathbb{D}^{1},{ }^{1}$ Dan-qing Song $\mathbb{D},^{2}$ Zhuo Chen, ${ }^{3}$ and Ju-wen Yang ${ }^{1}$ \\ ${ }^{1}$ College of Mining, Liaoning Technical University, Fuxin 123000, China \\ ${ }^{2}$ Department of Hydraulic Engineering, State Key Laboratory of Hydroscience and Engineering, Tsinghua University, \\ Beijing 100084, China \\ ${ }^{3}$ Laboratory of Hydraulics and Mountain River Engineering, Department of Geotechnical Engineering, Sichuan University, \\ Chengdu 610065, China
}

Correspondence should be addressed to Dan-qing Song; danqingsonglzu@163.com

Received 11 January 2020; Revised 27 May 2020; Accepted 3 June 2020; Published 30 June 2020

Academic Editor: Timo Saksala

Copyright ( 2020 Guang-wei Liu et al. This is an open access article distributed under the Creative Commons Attribution License, which permits unrestricted use, distribution, and reproduction in any medium, provided the original work is properly cited.

Rock slopes with weak intercalated layers could experience disturbance from various deep mining activities; however, their dynamic stability has not been thoroughly investigated. In this paper, the dynamic response characteristics and failure mechanism of the coal slopes with weak intercalated layers under blasting loads were studied by means of numerical analysis, shaking table tests, and field tests. The effects of dynamic loads with different frequencies on the dynamic response of the slope were analyzed, and the natural frequency of the slope was also determined. The results show that the dynamic amplification effect of the slope is smaller than that of the homogeneous slope, and weak layers weaken the wave propagation in the rock mass. Both experimental and field investigation results show that the slope's natural frequency was approximately $35 \mathrm{~Hz}$. The slope deformation decreased with the distance of the blasting source. Cracks appear along the weak interlayer firstly under the action of horizontal vibration; then, longitudinal cracks occur at the slope crest. With the increase of dynamic loads, cracks continue expanding, deepening, and penetrating in the main controlled weak interlayer; then, the sliding body presents tensile shear failure along the sliding surface. This study could provide insights into the understanding of the coal slope instability and failure mechanism; this could benefit the blasting operation of the coal slope in fields.

\section{Introduction}

According to the International Energy Agency (IEA, 2019), open-pit mining has made a significant contribution to the industry, producing around 17 billion tonnes of mineral fuels and industrial minerals annually [1]. With the sustainable demand for mineral resources and increasing consumption of shallow resources, most open-pit mines reach their designed ultimate depth. Under such a circumstance, deeper open-pit mining is performed on the higher and steeper slope [2-6], and good slope stability of open-pit mining is required to achieve its safety and financial targets $[7,8]$. Also, underground mining is combined with open-pit mining to produce more mineral resources.
Rock slopes could experience the disturbance from various deep mining activities in the process of combined open-pit mining and underground mining. In such deep mining process, the high-stress hard rock experiences various extreme events such as blasting operations, mechanical shock earthquakes, excavation unloading, and other dynamic disturbances around the deep underground rock [9-16], causing the significant change of the stress field and displacement field in the slopes and thus worsening the instability of slopes and landslide [17-20]. For example, on May 13, 2011, the north side of Shengli open-pit mine in Inner Mongolia, China, experienced a catastrophic landslide, which had a length of about $1.3 \mathrm{~km}$, an area of $0.886 \mathrm{~km}^{2}$, and a volume of approximately 85 million $\mathrm{m}^{3}$ [21]. Note that there also have been four small- and medium- 
scale landslides reported in this area during the past five years. Considerable economic and colliery losses have been caused. Through field investigation and disaster exploration, we found that the landslide could be triggered by the initiation and development of joints and structural planes in the slope and the subsequent blasting dynamic disturbance. Special attention should be thus paid to understanding the dynamic stability of coal slopes subjected to blasting dynamic disturbance.

The rock mass of the deep concave slope in the open-pit and underground combined mining is usually composed of multilayer soft and hard interlayer structural planes, of which the mechanical properties influence the slope deformation characteristics $[19,21,22]$. A number of studies have shown that structural planes are the main controlling factor in controlling coal slopes' local instability. For instance, the dynamic stability of coal slopes could be significantly affected by the mechanical behavior, structural form, and spatial distribution of structural planes [23, 24]. The shear failure of structural planes of coal slopes has been reported to cause severe slope instability problems [18]. Weak structural surfaces could be formed by multitudes of joints, and rock mass integrity could be impaired if they are widely distributed throughout rock slopes [25-27]. Given the uncertain geometric and mechanical parameters between them, such as uncertain directions, dip angles, and locations, the distribution of joints could be complex and difficult to understand $[26,27]$. Therefore, under blasting dynamic disturbance, the dynamic mechanical properties of coal slopes with weak intercalated layers could be rather complicated.

The dynamic response characteristics and stability of rock slopes, particularly those disturbed by excavation blasting, have been studied by several researchers. The rock stress measurements were performed by using techniques such as the compact conical-ended borehole overcoring (CCBO) technique, developed by Obara et al. [28]. Their measurement and 3D finite element analysis (FEA) results showed that the horizontal stress component is important in estimating the stability of rock slopes, even the mine is located near the top of a mountain. As the joints in rock could weaken structural surfaces, practical and realistic simulations of rock mass stability should include the influence of joints [29]. For soft-rock slopes, their instability and failure are mainly caused by the expansibility, dispersivity, extremely low shear strength levels, softening behavior, and preferential flows of soft-rock materials [30]. Given the stochastic behavior of the geomechanical properties (e.g., cohesion, friction coefficient, and unit weight) of the slope rock masses as well as the hydrogeological medium properties (e.g., hydraulic conductivity), probabilistic analysis has been applied to rock slope stability [31-33]. The risk models could be used to optimize design variables such as the slope angle through Monte Carlo simulation to fulfill the objective function that is formulated regarding the excavation cost [33].

To further understand the real dynamic response of rock slopes, shaking table tests have been used in the lab to reveal the variations of the dynamic response of rock slopes and their failure modes under seismic excitation [34-36]. Various types of lithology combinations and structures, slopes with discontinuous joints [37], and the slope with weak intercalation $[37,38]$ have been included in the lab test. In large-scale shaking table tests, the model size, the ground motion input parameters, and waveforms can be controlled based on the case studies to enable the slope dynamic responses to be measured to greater accuracy [39-44]. The testing results generally show that the slope angle, elevation, and surface microtopography have large impacts on the slope stability. The damage evolution process of the slope during earthquakes includes stages from the formation of tensile cracks in the strata and their propagation to the crest of the slope and sliding failure $[45,46]$. However, the above review shows that few studies focus on the understanding of the dynamic response characteristics of slopes under blasting loads; in particular, little research has been found on the analysis of the dynamic response of coal slopes with weak intercalated layers due to blasting loads.

In this paper, numerical simulations, shaking table tests, and field tests were performed to explore the dynamic stability of a coal rock slope with weak bedding layers under blasting loads. A case study on an actual engineering project was carried out. A mechanical slope model was first established based on LS-DYNA software platform to simulate the dynamic deformation characteristics of the slope with weak layers under blasting loads. The shaking table test was performed to investigate the dynamic failure evolution process of the slope under blasting dynamic loads in terms of the evolution rules of horizontal displacement and shear strain nephogram. Moreover, field tests and field investigations were used to verify the dynamic failure mechanism and deformation characteristics of the slope obtained from the numerical and shaking table test results. Our research aims to provide insights into the understanding of the dynamic response of coal slopes with weak intercalated layers due to blasting loads.

\section{Case Study}

As a typical coal slope with weak intercalated layers, Datang Shengli coalfield was selected for the case study. It is located in the middle and eastern part of the Inner Mongolia plateau, northern China (Figure 1), which belongs to the hilly plateau terrain with a height of $970.0-1,326.6 \mathrm{~m}$. The geomorphology of the slope is formed by structural denudation, mainly consisting of four geomorphic units: structural denudation topography, denudation accumulation topography, erosion accumulation topography, and karst platform [47].

Shengli east No. 2 open-pit mine is located in the transition zone of denudation accumulation terrain and low hilly terrain in the east of Shengli coalfield, with an elevation of 990.0-1,122.0 $\mathrm{m}$ and a relative elevation difference of $143.0 \mathrm{~m}$, shown as the "Study area" in Figure 1(a). The coalbearing strata in this area are lower coal-bearing member (K1bx12) of Xilin formation of Bayanhua group of lower cretaceous and upper coal-bearing member (K1bsh1) of Shengli formation. The coal seam of Shengli group is well developed, which is the primary coal-bearing section of this 


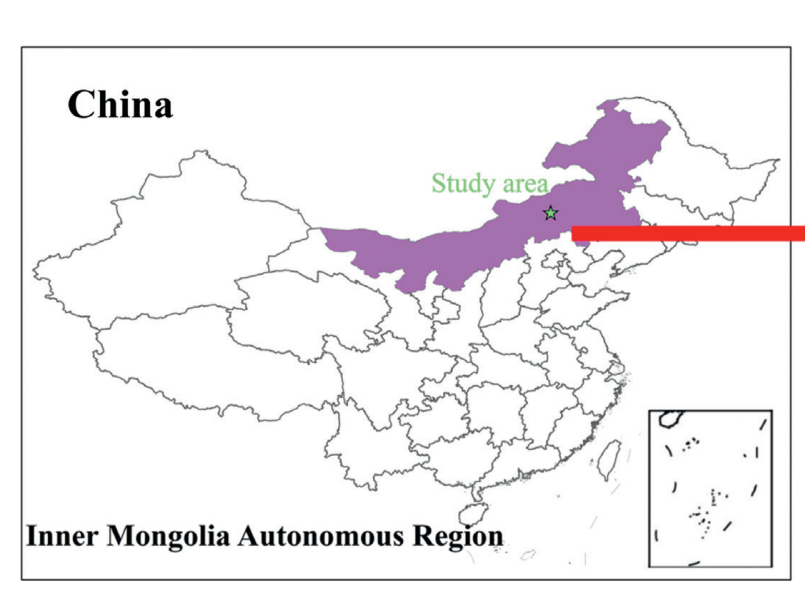

(a)

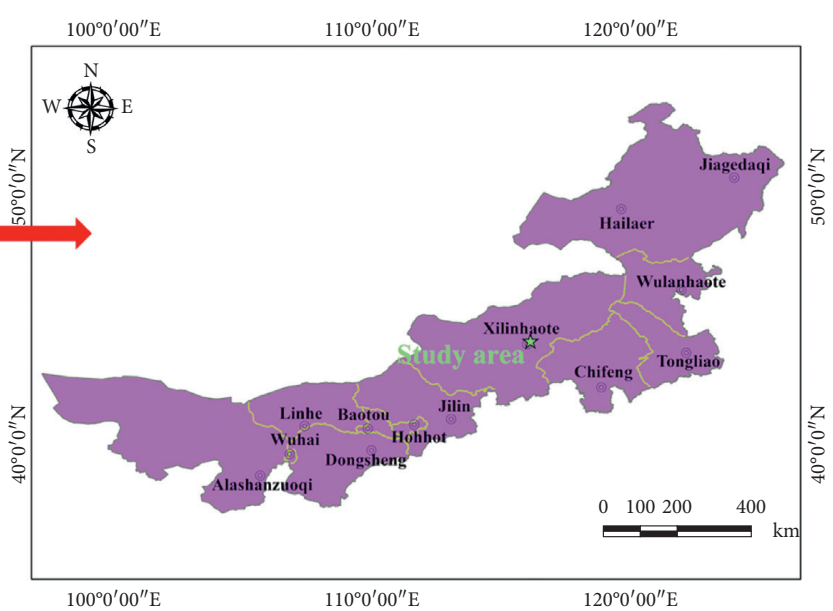

(b)

Figure 1: Location of the study area. (a) The study area in the Chinese map. (b) The study area in Inner Mongolia autonomous region.

section. The geological condition of the deformation area is rather complicated, considering the fact that there are several weak mudstone intercalations with low strength from top to bottom (i.e., four weak intercalations with gentle dip and one weak intercalation with steep dip).

Figure 2 shows the geomorphology of the slope. Table 1 shows the parameters of the corresponding rock samples. The mechanical properties of these rocks were obtained according to a series of laboratory tests, mainly including triaxial test, uniaxial compression test, and direct reduction test. Due to the rheology of the weak mudstone layer and the impact of blasting load, the shear strength of the coal rock slope is reduced. The weak mudstone layer is inclined, forming a natural potential slip surface, which is detrimental to the stability of the slope. In case of instability, the slope would slip along the weak mudstone layer. Hence, it is necessary to study the stability of the Datang south slope to better analyze the disaster mechanism of the slope with weak layers under the influence of dynamic loads.

\section{Wave Propagation Characteristics of the Slope under Blasting Loads}

3.1. Shaking Table Tests. As the monitoring points on the slope are 200-400 $\mathrm{m}$ away from the blasting location in our study, the slope is mainly subjected to the earthquake waves. When the seismic wave generated by blasting acts on the slope, the vibration wave propagates in the form of longitudinal and transverse waves, but the peak value of the horizontal vibration displacement is much larger than that of the vertical vibration displacement; that is, the slope vibration is mainly horizontal under the earthquake waves. According to the above-mentioned blasting characteristics, the shaking table test applies a simple vibration in the horizontal direction to simulate the vibration wave. The peak amplitude is $10 \mathrm{~mm}$, and the vibration frequency is between 10 and $40 \mathrm{~Hz}$. The testing results are used to generally understand the dynamic response characteristics and failure mechanism of coal slopes with weak intercalated layers under blasting loads.
3.2. Testing Models and Measurement System. The shaking table test was performed in the Institute of Mechanics, Liaoning Technical University, China. The bidirectional electric servo shaking table is $1.5 \mathrm{~m} \times 1.0 \mathrm{~m}$. Waves can be used as the input motions, and the effective frequency range is $0.5-50 \mathrm{~Hz}$. A maximum horizontal acceleration of $1.5 \mathrm{~g}$ and a maximum vertical acceleration of $1.2 \mathrm{~g}$ can be obtained. To simulate the semi-infinite foundation of the model, the effect of the boundary should be minimized when the experimental tank is designed. A rigid, sealed experimental tank comprising organic glass and carbon steel plates was developed for the tests, and its inner dimensions are $1.5 \mathrm{~m} \times 0.3 \mathrm{~m} \times 0.453 \mathrm{~m}$ (Figure 3 ). The slope is the prototype of the field slope, as shown in Figure 2. The materials and test parameters of the model were deduced based on the Buckingham $\pi$ theorem of similarity [48]. The acceleration $a$, mass density $\rho$, and dimension $L$ were selected as the fundamental parameters, with similarity ratios of $C_{a}=1$, $C_{\rho}=1$, and $C_{L}=25$, respectively. From the similarity calculation, the parameters of the rock mass simulation materials in the tests are listed in Table 1. The simulation materials were mainly formed from silica sand, calcium carbonate, and gypsum at different ratios, according to a series of triaxial tests. Cement, lime, kaolin, paraffin, and distilled water solution with retarder were selected as cementing materials. After stirring evenly, filling modeling was carried out according to the size of the model. The apparent density of similar materials is $1.5 \mathrm{~g} / \mathrm{cm}^{3}$. Mica powder is used for layering between layers. The thickness of each loading is generally $5-10 \mathrm{~mm}$.

In order to test the dynamic response of the slope when subjected to blasting vibrations with different frequencies, six identical models were prepared. To track the displacement of the slope subjected to seismic loads, the optical measurement technique analysis was employed. The displacement data were collected by using XTDIC measurement system, including a camera with two million pixels, and its acquisition frequency is $50 \mathrm{~Hz}$, as shown in Figure 3. The camera was used to collect the displacement data in $x$ and $z$-directions. The highest acquisition frequency of 


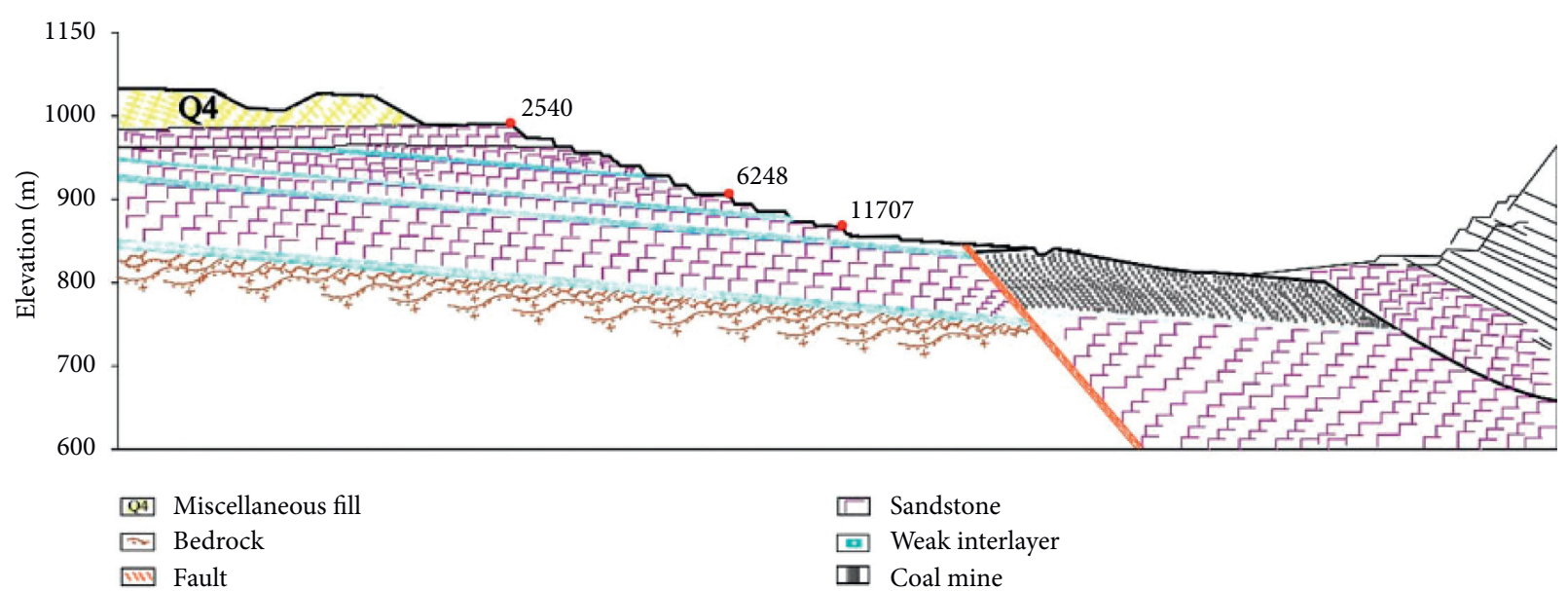

(a)

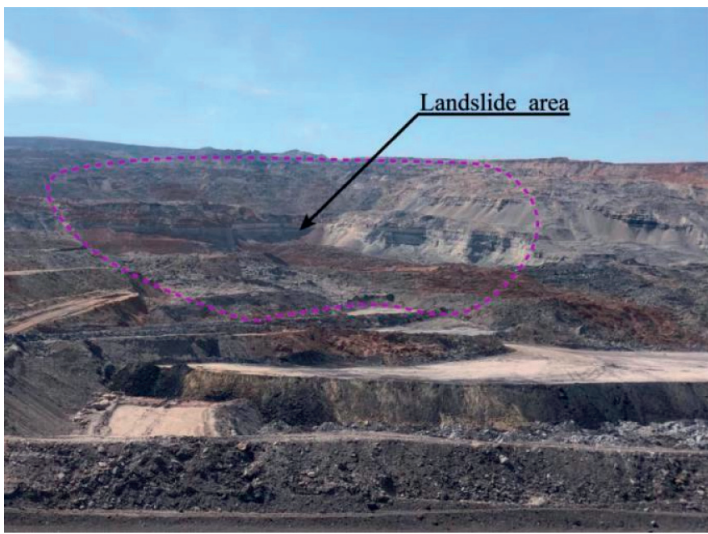

(b)

Figure 2: The geomorphology of the slope. (a) The geological section of east No. 2 slope. (b) The topography of the slope.

TABle 1: Material parameters in the case study.

\begin{tabular}{lcccc}
\hline Type & Cohesion $(\mathrm{kPa})$ & Internal friction angle $\left(^{\circ}\right)$ & Bulk density $\left(\mathrm{kg} / \mathrm{m}^{3}\right)$ & Elasticity modulus $\left(10^{4} \mathrm{MPa}\right)$ \\
\hline Abandoned material & 70 & 19 & 17,500 & 0.4 \\
Loess & 230 & 24 & 18,000 & 0.02 \\
Sand mudstone & 1,700 & 27 & 20,200 & $0.8-2.3$ \\
Weak layer & 28 & 13 & 20,000 & 0.01 \\
Coal mine & 500 & 29 & 15,000 & $0.38-2.1$ \\
Fault & 6 & 12 & 19,000 & 0.01
\end{tabular}

XTDIC measurement system is $340 \mathrm{~Hz}$, and its measurement error within the range of $5 \mathrm{~m}$ is about $0.05-0.1 \mathrm{~mm}$. The twodimensional displacement of every marked point can be obtained in the tests, and the layout scheme of the marked points is shown in Figure 3. The XTDIC measurement system is based on binocular stereo vision technology, using the high-speed camera to collect the real-time images in all stages of the deformation object. The accurate recognition of marker points or digital speckle was used to realize stereo matching, including coding and noncoding marker points, to calculate the deformation of the object. This method has characteristics of high precision, high speed, and easy operation and noncontact. Figure 3 illustrates the setup for measuring displacement. The cameras were stationary after calibration; a few states were collected as a benchmark when the model was static. When the shaking table began to shake, the cameras began to collect displacement data. Finally, the spatial coordinates of each state of the mark points were calculated to analyze displacements of the marker points; i.e., the displacement data were obtained based on the analysis of the change of coordinate values. Note that the data analysis of XTDIC measurement system supports coordinate transformation.

Blasting vibration is mainly the horizontal displacement produced by the longitudinal wave. Thus, the experiment mainly simulates the deformation and failure of the slope 


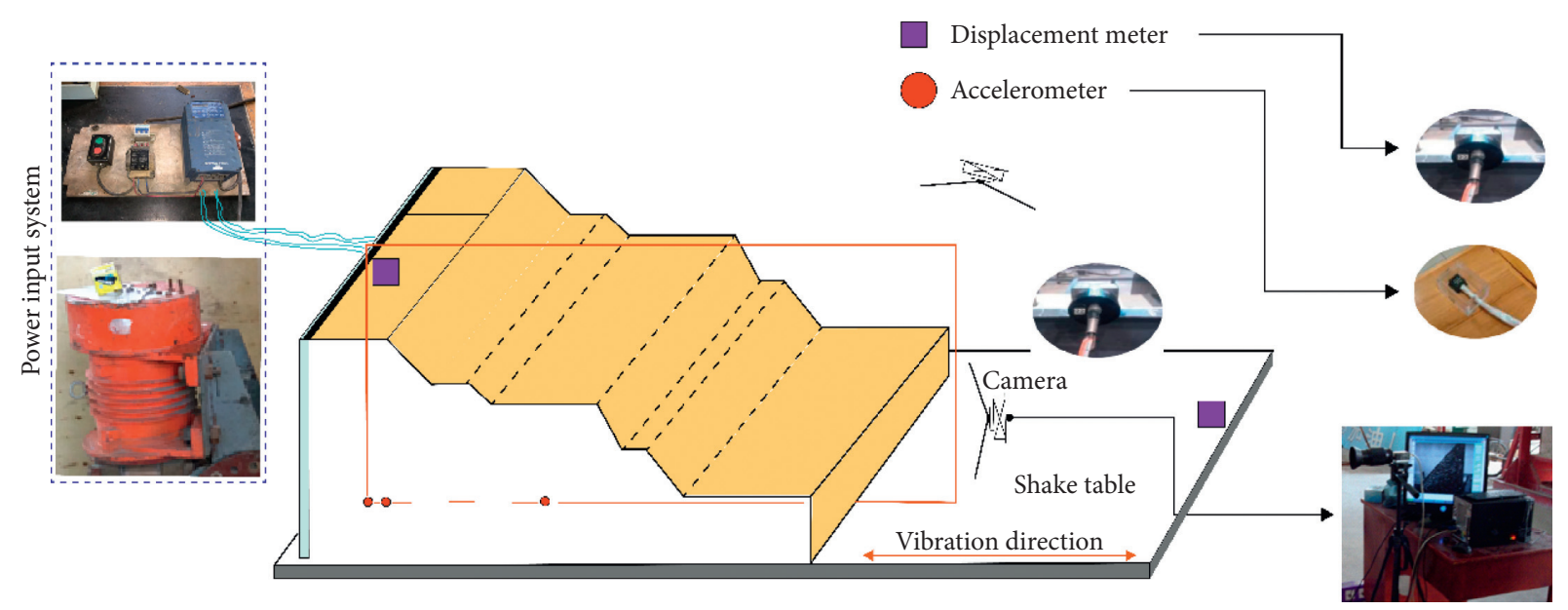

FIgURE 3: Test equipment and monitoring point layout.

model under the action of horizontal dynamic force. The horizontal power input by the model is the horizontal force provided by adjusting the current frequency of the input vibration motor, changing the rotation speed of the motor, and driving the eccentric wheel to rotate. The horizontal vibration wave with a peak amplitude of $10 \mathrm{~mm}$ was applied in this test. In order to simulate the failure characteristics of the slope under the action of blasting waves of different frequencies, the maximum input velocity at the bottom of the slope was $0.75 \mathrm{~cm} / \mathrm{s}$ by controlling the vibration table, and the frequency was simple harmonic of $15 \mathrm{~Hz}, 20 \mathrm{~Hz}$, $25 \mathrm{~Hz}, 30 \mathrm{~Hz}, 35 \mathrm{~Hz}, 40 \mathrm{~Hz}$, and $45 \mathrm{~Hz}$, and the measurement points were monitored by the digital sputtering method. Additionally, the acceleration data from the test should be preprocessed by filter and baseline calibration. MATLAB was used to compile the Chebyshev II bandpass filter in order to filter the wave and obtain the effective waveform frequency.

3.3. Dynamic Response Characteristics of the Slope. In order to study the influence of input wave frequency on slope dynamic response characteristics, the displacement and shear strain nephograms of slope under dynamic loads with different frequencies $(15-30 \mathrm{~Hz})$ are shown in Figures 4 and 5. The results show that the dynamic deformation response of the slope is rather different under the action of vibration waves with different frequencies. With the continuous increase of the loading time, the slope surface and the top of the slope became slightly loose, and the horizontal displacement appeared at each step without large damage.

The weak interlayer and the vicinity of the fault were slightly staggered with vibration, and debris fell with vibration. Figures 5 and 6 show that when the vibration frequency is $35 \mathrm{~Hz}$, the cracks appear and penetrate rapidly at the fault outcrop and weak interlayer junction. At the same time, some small cracks were generated on the slope surface and the top of the slope, and the cracks gradually began to develop. With the increase of vibration time, the particle displacement at about $0.5 \mathrm{~s}$ was amplified due to resonance, and the slope was suddenly seriously damaged and collapsed. Figure 5(d) shows that the shear strain first appears in the weak structural plane inside the slope. With the continuous increase of vibration time, vertical cracks are formed at the top of the slope of each step, and the internal dislocation of the slope along the direction of shear belt is more and more obvious, resulting in the shear failure in other places in the direction of the shear belt that has not been damaged, and the shear belt looks more continuous. Finally, a shear outlet appears at the junction of the weak layer at the bottom of the slope and the fault, and at the same time, it is connected with the fractures in the vertical direction.

To further study the dynamic response characteristics of the slope, take a point at the top of the slope as an example, its displacement-time history curves under the action of vibration waves of different frequencies are shown in Figure 7. The results show that with the increase of the input frequency, the displacement of the measuring point also increased. However, when the frequency was $35 \mathrm{~Hz}$, there was an anomaly and the displacement of the measuring point suddenly increased up to $18.9 \mathrm{~mm}$, indicating that the shape of slope or the parameters of rock and soil material change greatly, and the slope is destroyed dynamically.

The above analysis shows that the dynamic damage evolution process of the slope can be summarized as follows: first of all, shear bands are formed in the weak layers due to horizontal vibration. Secondly, vertical tension cracks are generated at the top of the slope, and the two gradually develop with the action of vibration until they are broken through, forming a fracture plane composed of tension shear. It is not a traditional shear slip plane, nor a tension crack generated by acceleration amplification at the top of the slope, but a combination of the two. Therefore, our shaking table test shows that when the slope model is subjected to vibration loads with different frequencies, the integrity is still good, although there are slight degrees of damage. When the vibration frequency is $35 \mathrm{~Hz}$, the slope suddenly collapses; this could be caused by resonance. Therefore, it can be determined that the natural frequency of the slope model is about $35 \mathrm{~Hz}$. 


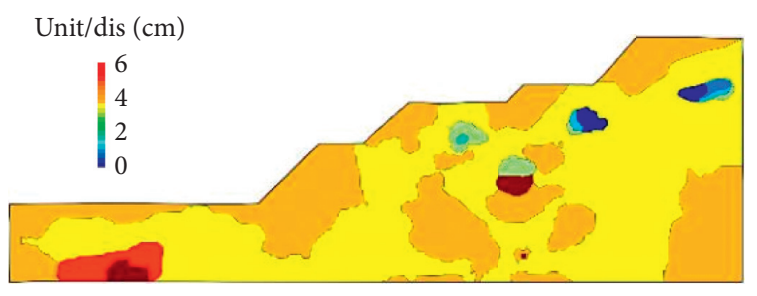

(a)

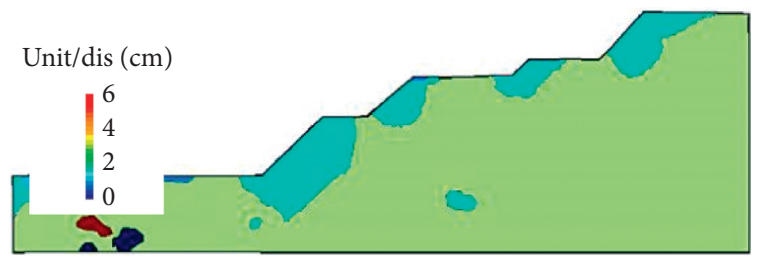

(c)

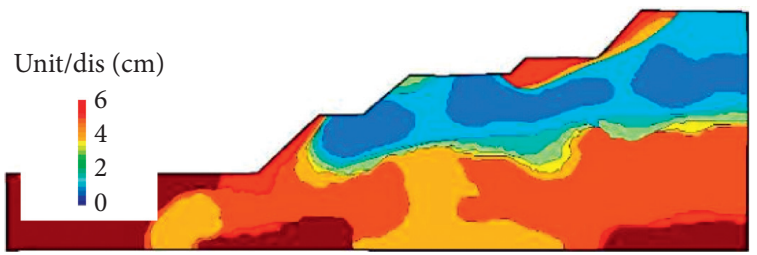

(e)

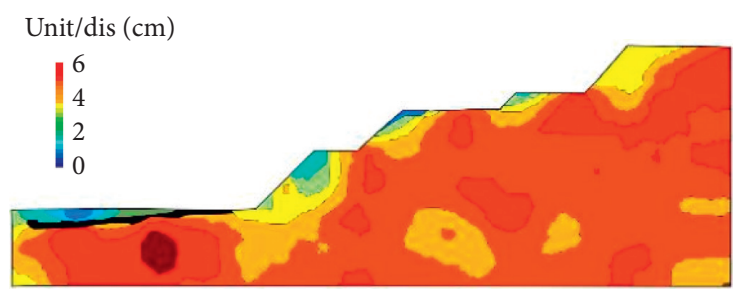

(b)

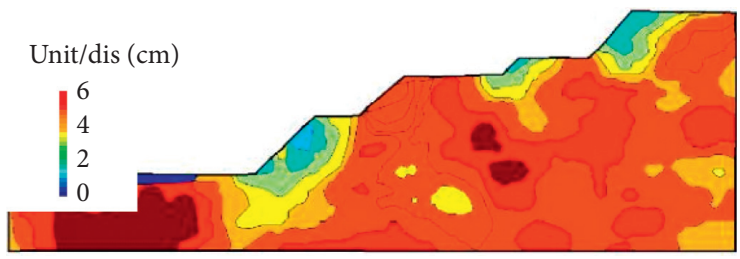

(d)

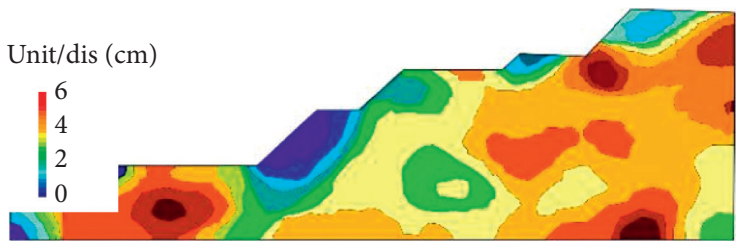

(f)

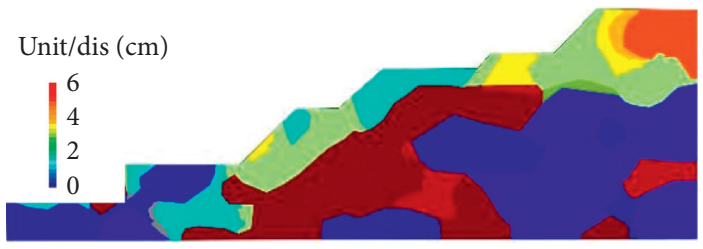

(g)

FIGURE 4: Horizontal displacement nephograms at different frequencies in the $x$-direction. (a) $15 \mathrm{~Hz}$. (b) $20 \mathrm{~Hz}$. (c) $25 \mathrm{~Hz}$. (d) $30 \mathrm{~Hz}$. (e) $35 \mathrm{~Hz}$. (f) $40 \mathrm{~Hz}$. (g) $45 \mathrm{~Hz}$.

3.4. Numerical Model. Finite element method (FEM) dynamic analyses were then used to simulate the wave propagations through rock masses; thus, the internal, continuous stress development in rock masses can be characterized and understood. Due to the capabilities of transient dynamics simulation, the LS-DYNA program was adopted as a solver to conduct the FEM dynamic analyses. This program, which mainly uses Lagrange, ALE, and Euler algorithms, is fully functional with geometric nonlinearity (e.g., large displacement, large rotation, and large strain), material nonlinearity, and contact nonlinearity. It not only provides an explicit solution but also generates implicit solutions concurrently.

The rock and explosive elements were simulated by the ALE algorithm of the 4-node solid element PLANE62, the explosive element, and the exploded element share nodes. This setting could have the fastest calculation speed, and it can continue the calculation even if the contact element has been broken. There are two kinds of rock and soil parameters in this study: weak-layer visco-elastoplastic materials and other rock mass plastic materials. The constitutive model of weak-layer viscoelastic materials is the linear viscoelastic model proposed by Herrmann and Peterson [49].
For other rock mass plastic materials, *MAT_ PLASTIC_KINEMATIC material was selected as the simulated material, and the yield condition is

$$
\begin{aligned}
\varphi & =\frac{1}{2} \xi_{i j}^{2}-\frac{\sigma_{y}^{2}}{3}=0, \\
\xi_{i j} & =s_{i j}-a_{i j}, \\
\sigma_{y} & =\left[1+\left(\frac{\dot{\varepsilon}_{i j}}{C}\right)^{1 / P}\right]\left(\sigma_{0}+\beta E_{P} \varepsilon_{\mathrm{eff}}^{p}\right),
\end{aligned}
$$

where $P$ and $C$ are input constants and $\dot{\varepsilon}_{i j}$ and $\varepsilon_{\text {eff }}^{p}$ are the strain rate and effective plastic strain, respectively.

LS-DYNA provides the material model of high-energy explosives and the state equation of various explosives, which can accurately simulate the whole shockwave propagation process as well as the transient response process of the structure. The explosive parameters are as follows: the *MAT_HIGH_EXPLOSIVE_BURN material was selected in the model, and the density, velocity, and detonation pressure are $1.69 E+3 \mathrm{~kg} / \mathrm{m}^{3}, 8,310 \mathrm{~m} / \mathrm{s}$, and $30.45 \mathrm{GPa}$, respectively. The control equation of explosive materials is as 


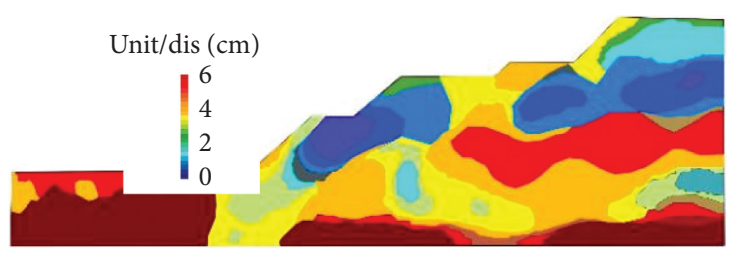

(a)

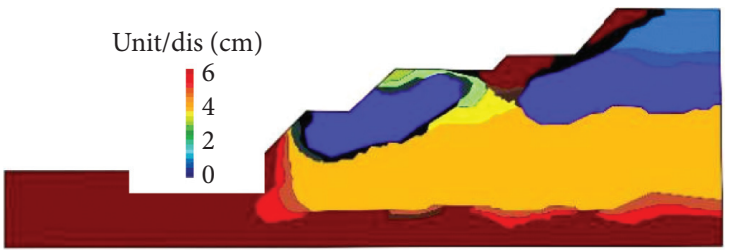

(c)

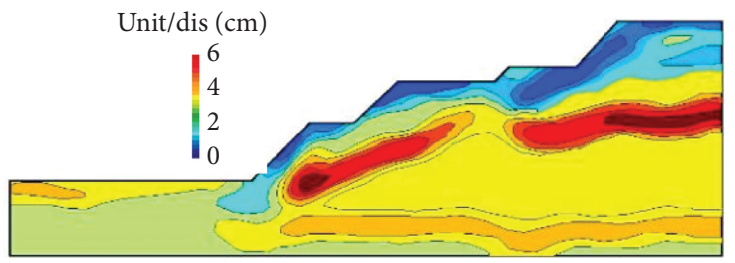

(e)

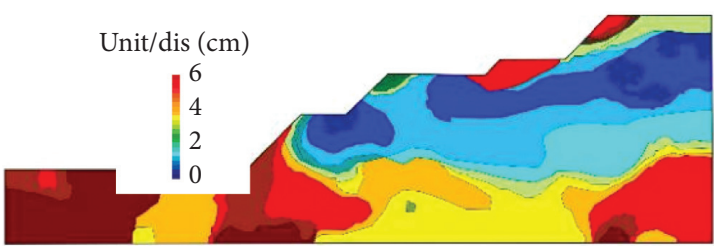

(b)

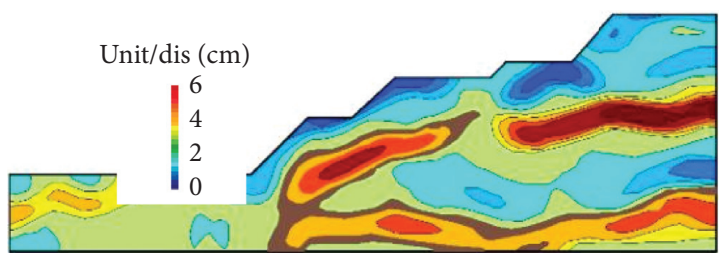

(d)

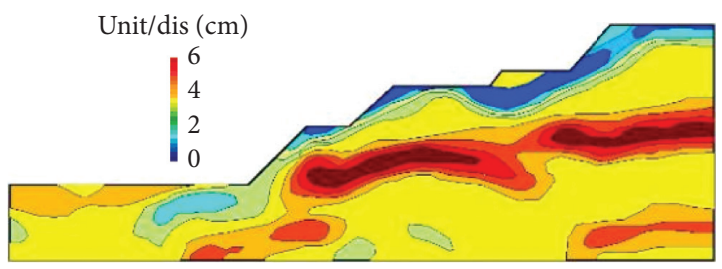

(f)

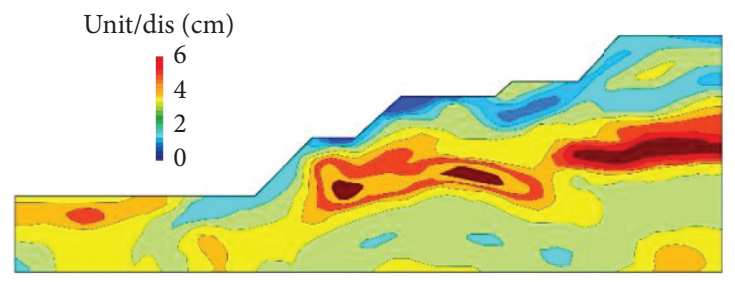

$(\mathrm{g})$

Figure 5: Evolution process of the slope under the input dynamic load with a frequency of $35 \mathrm{~Hz}$ during the whole failure process. (a-c) Displacement evolution. (d-g) Shear strain evolution.

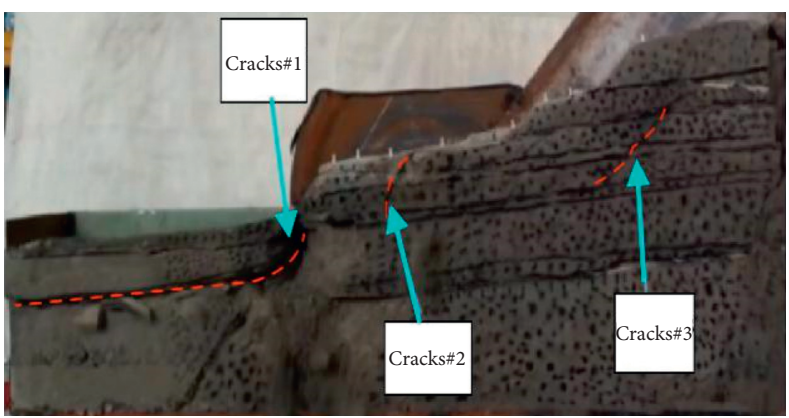

FIGURE 6: Distribution of cracks in the slope under the input dynamic load with a frequency of $35 \mathrm{~Hz}$. 


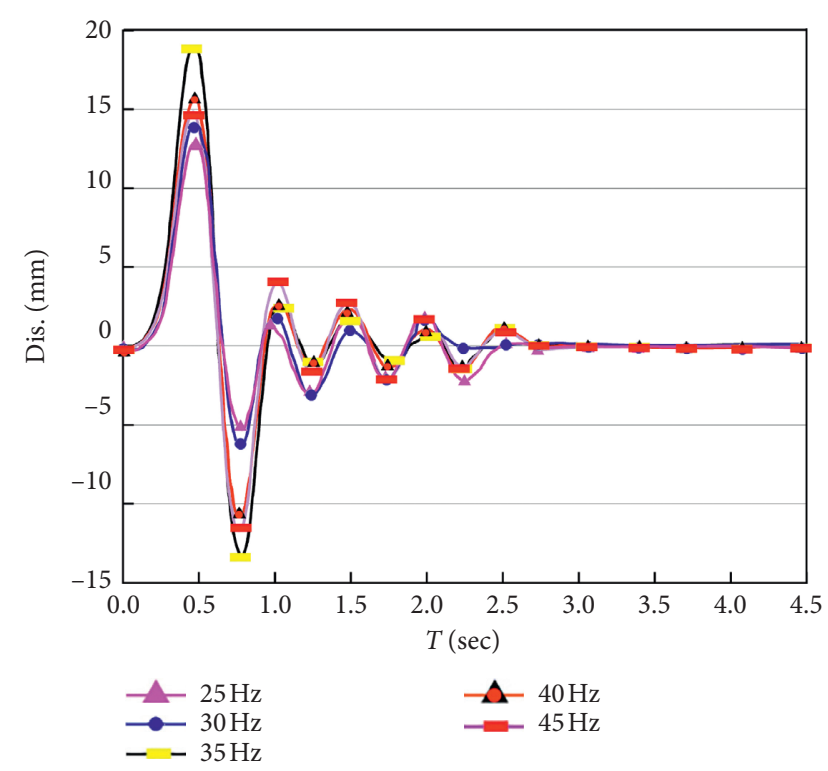

FIGURE 7: Displacement-time history curves of a point at the slope surface under the action of vibration waves of different vibration frequencies.

follows: when the explosion happens, the detonation wave front satisfies the following equation:

$$
\left\{\begin{array}{l}
\rho_{D}=\frac{k+1}{k} \rho_{e}, \\
u_{D}=\frac{1}{k+1} D, \\
C_{D}=\frac{k}{k+1} D, \\
p_{D}=\frac{1}{k+1} \rho_{e} D^{2},
\end{array}\right.
$$

where $p_{D}, \rho_{D}, \mu_{D}$, and $C_{D}$ are the pressure, density, particle velocity, and sound velocity on the detonation wave front, respectively; $k, D$, and $\rho_{\mathrm{e}}$ are the polytropic exponent, explosive detonation rate, and explosive density, respectively. After the initiation of high-energy explosives, the pressure $p$ of the inner element of the explosive was calculated by the JWL equation, which describes the change of chemical energy when the explosive is exploded.

In order to simulate the dynamic failure mechanism of the slope with weak intercalated layers under blasting dynamic loads, one numerical model with the homogeneous slope (i.e., Model 1) and the other one with the slope having weak interlayers (i.e., Model 2, as shown in Figure 8) were established. The length of the slope model was $1,500 \mathrm{~m}$, and the heights of the left side and the right side were $453 \mathrm{~m}$ and $290 \mathrm{~m}$, respectively. The aperture and depth of the blasting hole were $0.3 \mathrm{~mm}$ and $15 \mathrm{~m}$, respectively. The plugging depth was $3 \mathrm{~m}$, and the mesh size was set at $2.5 \mathrm{~m}$. The left and right boundaries constrain the $x$-direction displacement. The bottom boundary constrains the $y$-direction displacement.
The left and right sides and the lower boundary are nonreflective boundaries. The peak velocity of the input blasting wave is $0.75 \mathrm{~cm} / \mathrm{s}$. Note, in section shaking table tests, blasting waves with a series of vibration frequencies including $15 \mathrm{~Hz}, 20 \mathrm{~Hz}, 25 \mathrm{~Hz}, 30 \mathrm{~Hz}, 35 \mathrm{~Hz}, 40 \mathrm{~Hz}$, and $45 \mathrm{~Hz}$ were used to test the dynamic response characteristics of the slope in our experiment. The testing results showed that, when the frequency was $35 \mathrm{~Hz}$, the slope collapsed due to the resonance (also the maximum horizontal displacement of the monitoring points of $18.29 \mathrm{~mm}$ occurred), indicating that the natural frequency of the slope model is about $35 \mathrm{~Hz}$. Hence, the blasting wave with $35 \mathrm{~Hz}$ frequency was used in our numerical model to simulate the dynamic failure mechanism of the slope with weak intercalated layers under blasting dynamic loads.

3.5. Numerical Results. The equivalent stress nephograms of homogeneous slope (Model 1) and slope with weak intercalated layers (Model 2) under blasting loads are, respectively, shown in Figures 9(a) and 9(b). Figure 9(a) shows that the detonation wave took the explosion source as the center and spread outwards in a spherical manner. The failure area of the explosion source gradually increased, forming the fracturing and crushing area, and the rock mass was completely destroyed. With the distance from the explosion source, the shock wave decayed into a stress wave and failed to crush the rock mass directly. However, the tangential tensile stress of the rock mass exceeded its tensile strength, and tensile failure occurred in the surrounding rock. The red region shows that the maximum tensile stress was first reached and the rupture occurred. With the increase of the sphere radius, the reflection wave was generated when it reached the boundary transits.

Compared to Model 1 results, the weak interlayer in Model 2 had an obvious barrier effect on the stress wave propagation when the explosion wave reached the weak interlayer. When the stress wave propagated from the hard rock to the weak interlayer, the wave resistance of the weak interlayer was less than that of the hard rock. When the stress wave reached the interface of the two media, part of the wave energy entered the soft medium, leading to the attenuation of the stress wave. When the stress wave propagated from the weak interlayer to the hard rock, a large amount of stress wave energy was reflected at the interface of the two media, and only a small number of waves penetrated the interface and entered the hard rock. This phenomenon shows that the weak interlayer not only effectively weakened the stress of the slope under blasting loads but also changed the mechanical properties of the weak interlayer, making the slope easier to produce creep deformation.

The displacement-time history and velocity-time history of the three typical monitoring points (i.e., 2640, 6248, and $11707)$ of the two models in the $x$ - and $y$-directions are shown in Figures 10 and 11. The changes of peak ground acceleration (PGA) and peak ground displacement (PGD) at the points are shown in Figure 12. As shown in Figure 10, the horizontal and vertical displacements of the monitoring points of the slope with weak interlayers under blasting loads 


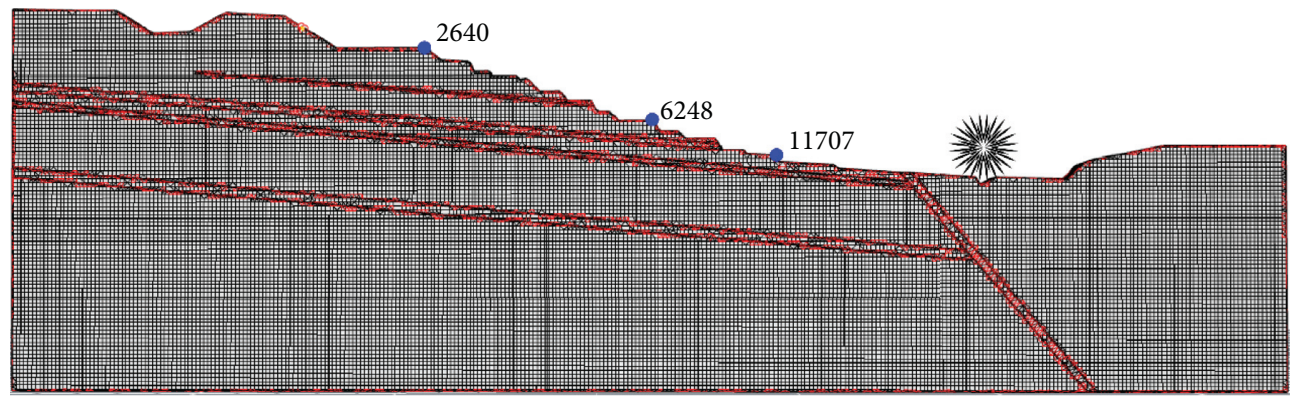

- Monitoring point

Effect of blasting

FIgURE 8: The mesh model used in the calculations.
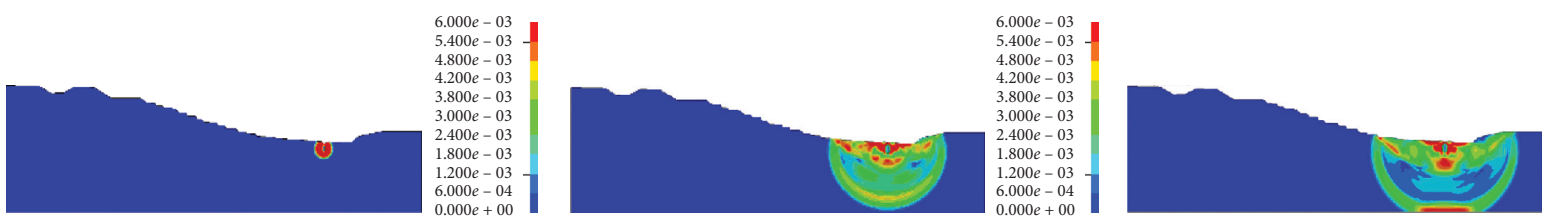

$6.000 e-03$
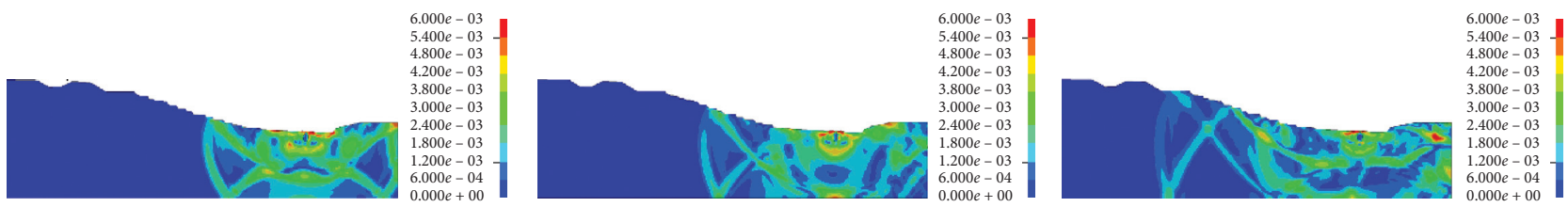

(a)
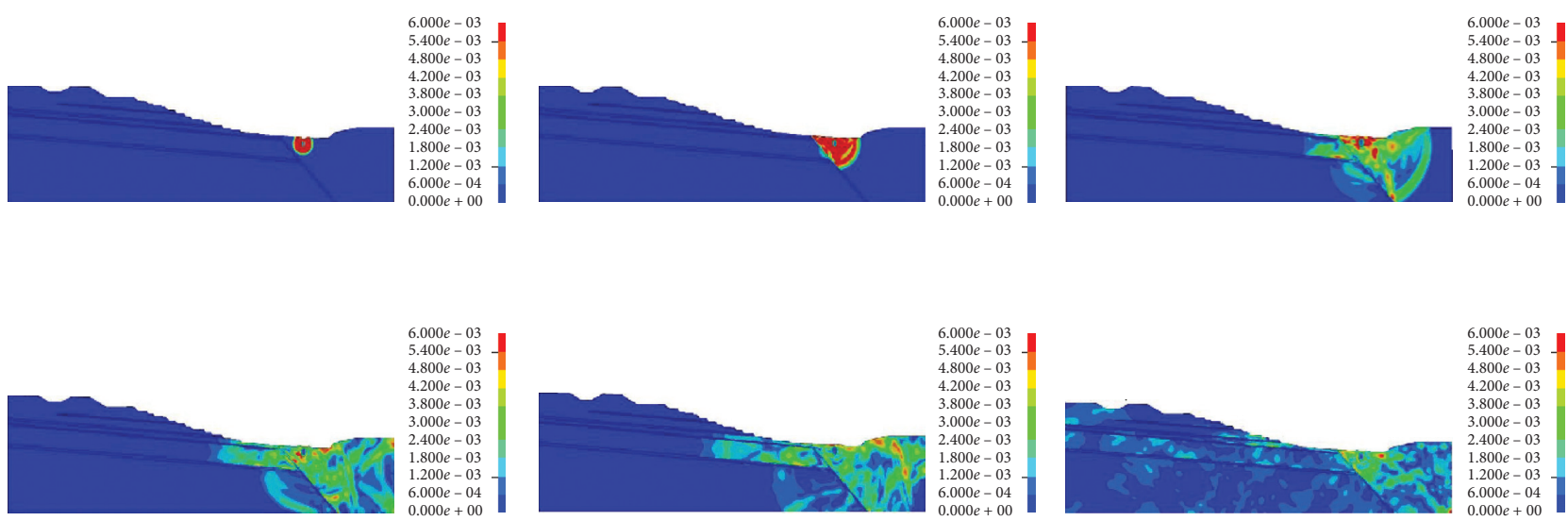

(b)

FIGURE 9: Equivalent stress nephograms of two slopes under blasting loads. (a) The homogeneous slope. (b) The slope with weak intercalated layers.

were much less than those of the homogeneous slope. For example, the overall horizontal displacement of Point 1 (i.e., 2640) decreased by $37.43 \%$ from $1.79 \mathrm{~cm}$ to $1.12 \mathrm{~cm}$, and the overall horizontal displacement of Point 2 (i.e., 6248) decreased from $3.37 \mathrm{~cm}$ to $1.58 \mathrm{~cm}$, decreasing by $53.11 \%$. This decrease is caused by the damping effect of weak interlayers on the propagation of the stress waves. With the increase of the distance from the explosion source, the horizontal displacement values decreased gradually. Also, there is a delay in the occurrence of velocity in Model 2, as shown in Figures 11(c) and 11(d).
Figures 10-12 also show that the blasting wave amplitude was extremely large in the area close to the explosion source. As the explosion source distance increased, the maximum value of the vibration amplitude of the particle decreased and tended to be stable with the increase of the distance. From the results of Figures 10(a)-10(d) and Figures 11(a)11(d), we obtained the PGA and PGD curves of two models, which are shown in Figure 12. Figure 11 shows that the horizontal vibration velocity amplitude of the particle at the same point was larger than the vertical vibration velocity, 


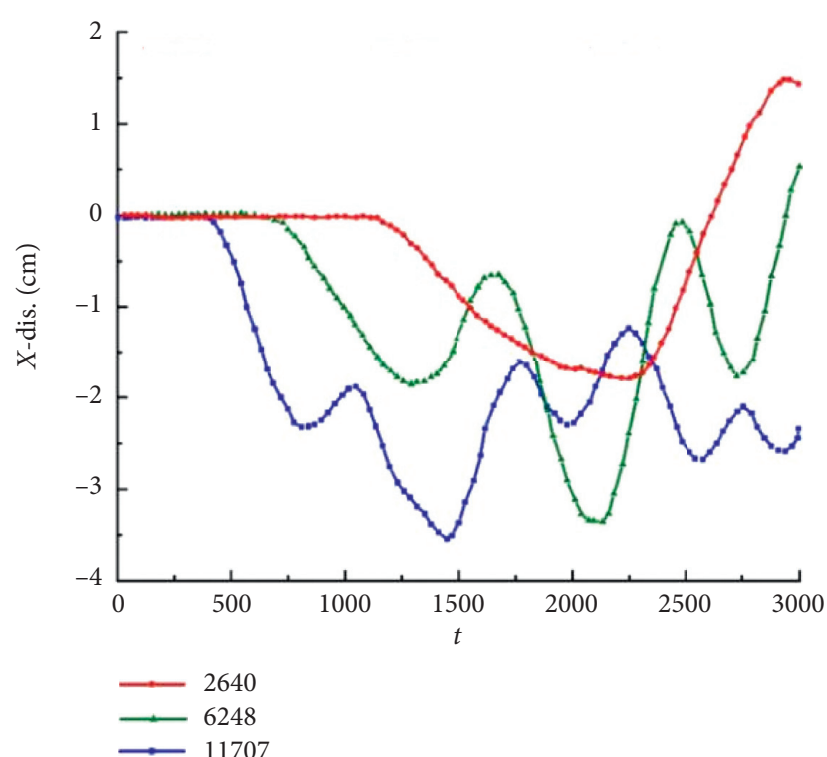

(a)

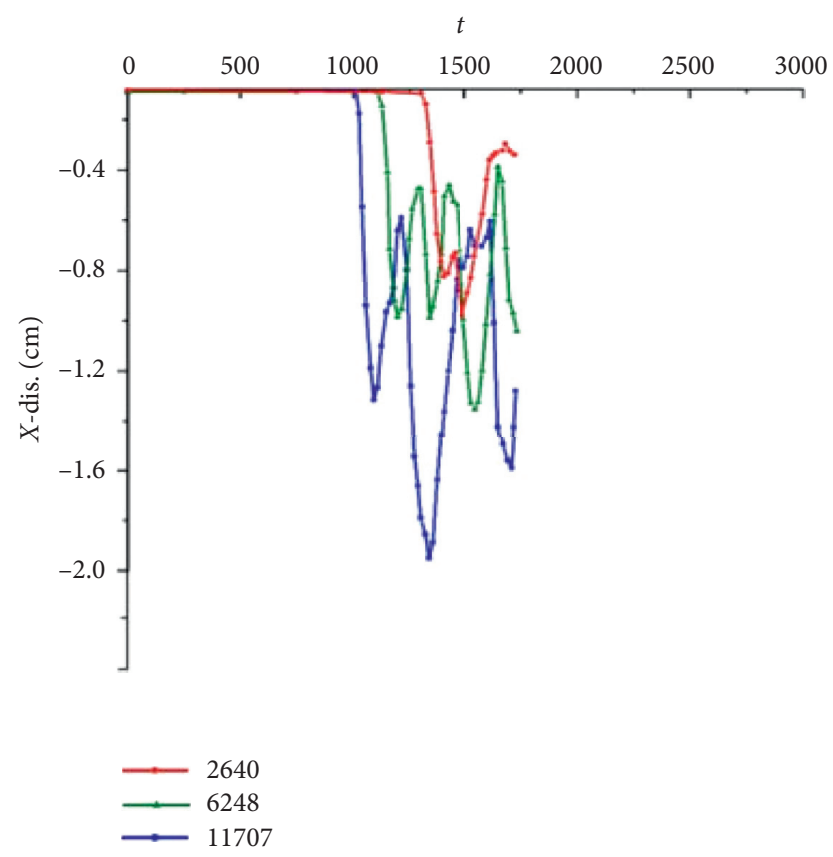

(c)

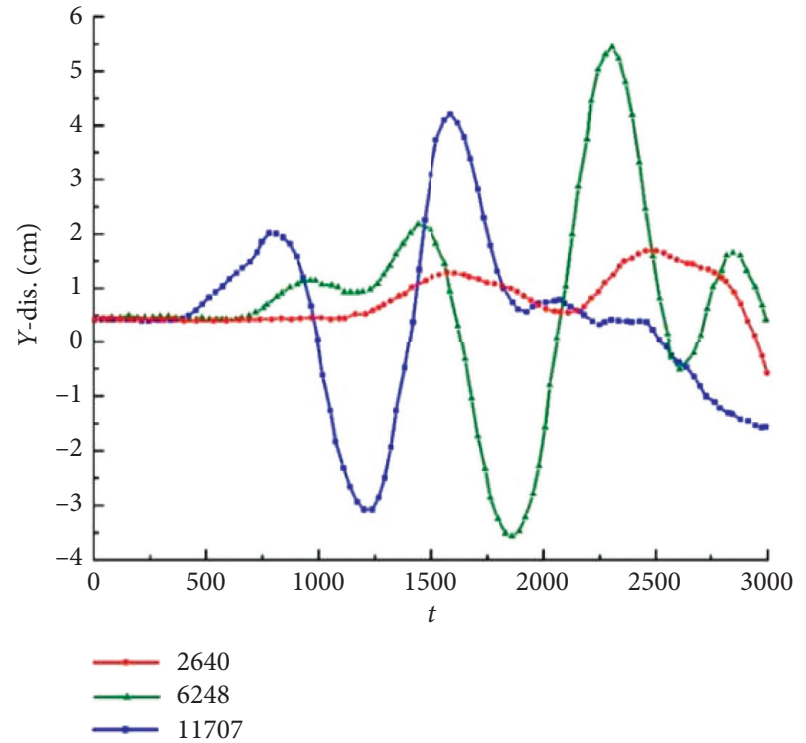

(b)

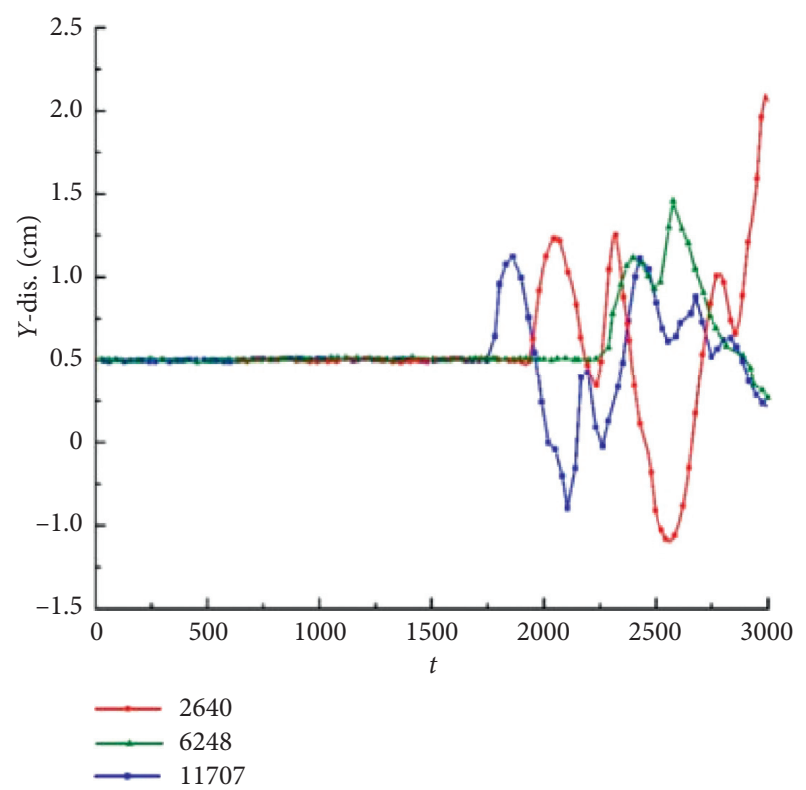

(d)

Figure 10: Displacement-time history curves of different monitoring points. (a) Model 1, $x$-direction. (b) Model 1, $y$-direction. (c) Model 2 , $x$-direction. (d) Model 2, $y$-direction.

and the horizontal PGA and PGD were approximately twice as much as the vertical vibration amplitude. Both the horizontal and vertical acceleration-time history curve decayed rapidly. After about 3,000 microseconds, the vibration amplitudes of the particle decayed to an extremely small level; thus, they are not shown in Figure 11. After that, the particle would make a slight vibration near the equilibrium position until the energy dissipation was complete. The particle vibration amplitude of Model 2 is significantly less than that of Model 1, which is due to the damping effect of weak interlayers on the propagation of the stress waves.

\section{Field Blasting Vibration Monitoring Tests and Field Investigations}

4.1. Blasting Vibration Monitoring Test. Figure 13 shows the blasting vibration monitors that include the NUBOX-6016 intelligent vibration monitor and the supporting speed sensor produced by Sichuan Top Measurement and Control Technology Co., Ltd. They are mainly used for recording signals such as blasting, vibration, and noise. Deep hole blasting was adopted in our tests. According to the vibration measurement data in the trial and error tests, the frequencies 


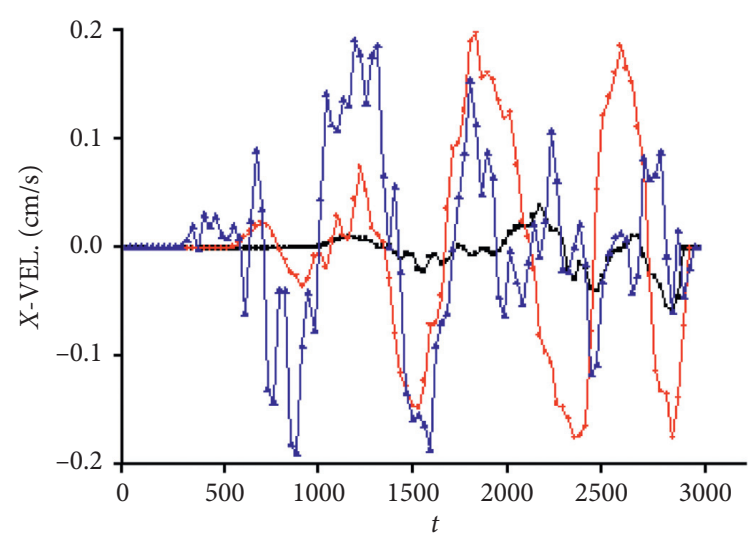

(a)

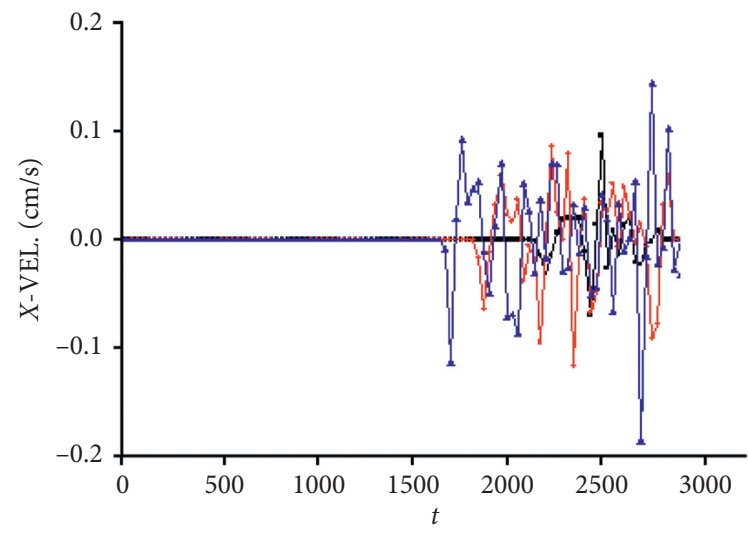

(c)

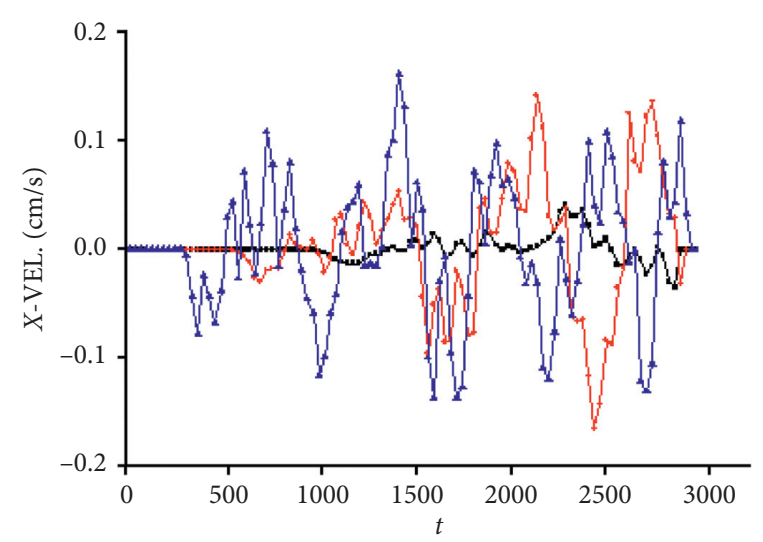

(b)

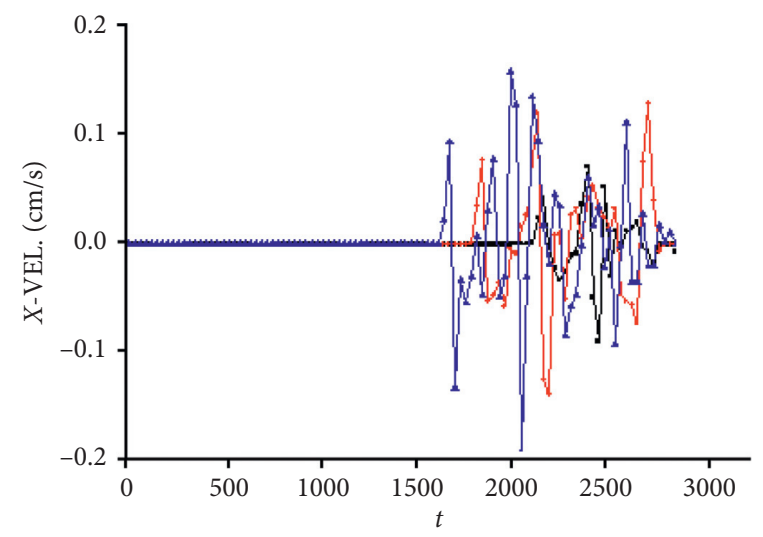

(d)

Figure 11: Velocity-time history curves of different monitoring points. (a) Model 1, x-direction. (b) Model 1, $y$-direction. (c) Model 2, $x$-direction. (d) Model 2, $y$-direction.

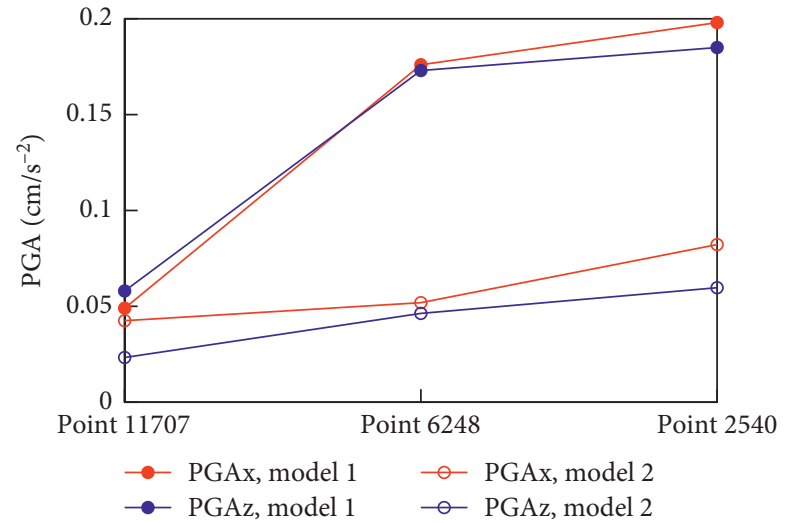

(a)

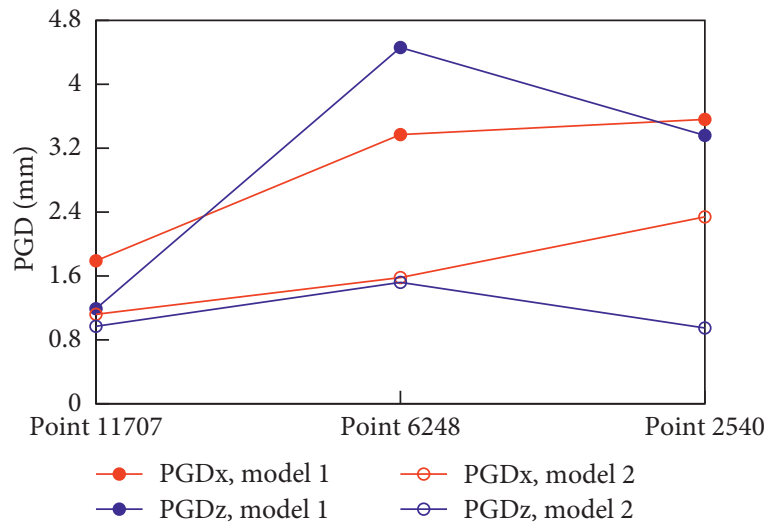

(b)

FIgUre 12: Changes of PGA and PGD of the slope under blasting loads. (a) PGA. (b) PGD.

of blasting vibration were kept at $7-18 \mathrm{~Hz}$; hence, when judging the impact of blasting vibration on the slope and newly poured mass concrete, the frequency should be $<10 \mathrm{~Hz}$ or $10-50 \mathrm{~Hz}$ [49].

The displacement sensor is required to be rigid and fixed with the binding surface. As the open-pit mine is a soft-rock slope, the sensor area is small, and the mass is light, and it is difficult to form a rigid fixation with the contact surface of loose soft rock. In order to fix the sensor, the bedrock was first bonded with the cement column by using gypsum. The sensor was then bonded to the top surface of cement column by using gypsum.

During the blasting operation of the slope, the displacement sensor was fixed on the side slope for data 


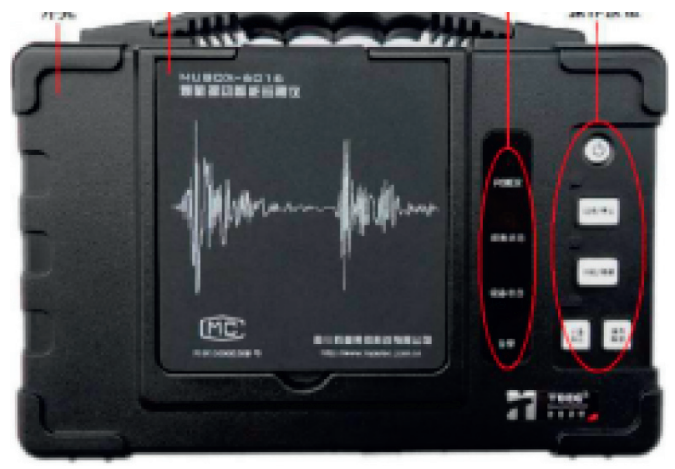

(a)

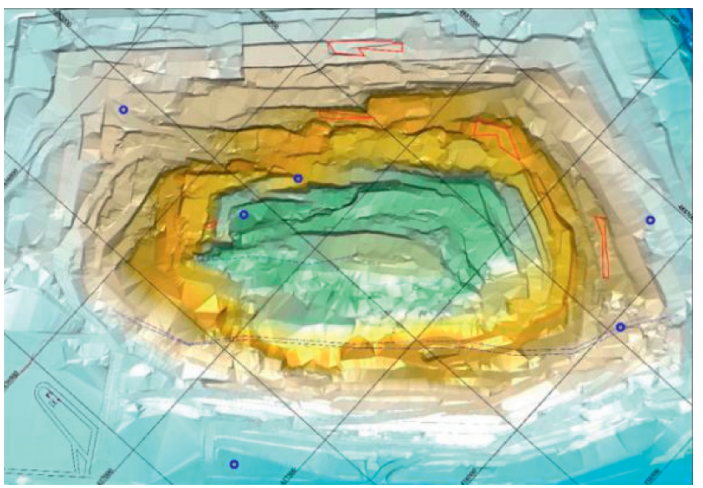

(c)

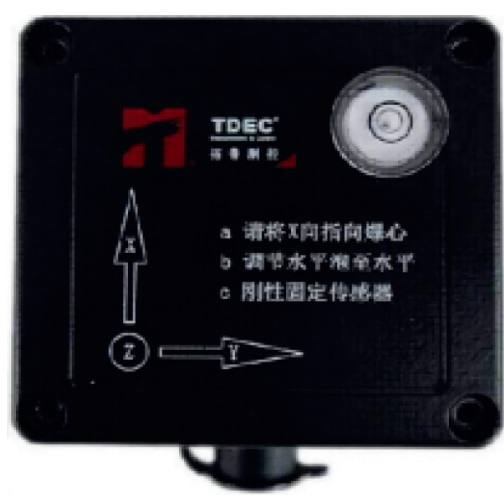

(b)

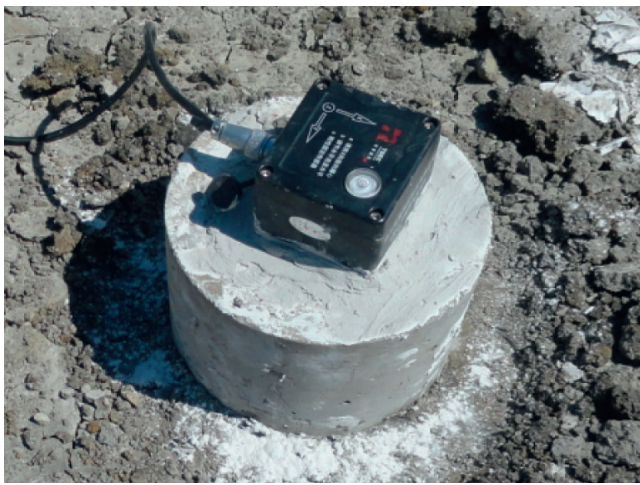

(d)

Figure 13: Field testing equipment. (a) NUBOX-6016 Intelligent vibration monitor. (b) Three-dimensional velocity sensor. (c) Global layout diagram. (d) Displacement sensor.

monitoring, as shown in Figure 13, to analyze the dynamic deformation characteristics of the slope under the action of blasting. The relative maximum displacements of the monitoring point at the top of the slope during the two blasting operations in May and June are shown in Figure 14. The results show that, under the influence of blasting vibration, the cumulative maximum creep displacement of the slope monitoring point is approximately $57 \mathrm{~mm}$ and $48 \mathrm{~mm}$. The displacement variations follow the typical development of three stages of creep: initial creep, stable creep, and accelerated creep. Additionally, to analyze the impact of blasting wave frequency on the dynamic response characteristics of the slope, the displacement development of a monitoring point subjected to different blasting loads with frequencies from 25 to $45 \mathrm{~Hz}$ is presented in Figure 15. The field test results show that the displacement of the monitoring points under the action of blasting waves with different frequencies is different at the early age of around 3 seconds. The maximum horizontal displacement of the monitoring points is $18.29 \mathrm{~mm}$ when the frequency of the main vibration is $35 \mathrm{~Hz}$, indicating that the natural frequency of the slope is about $35 \mathrm{~Hz}$. Thus, the slope is most prone to instability failure under the action of this vibration frequency, which is consistent with the results of the numerical simulation and the shaking table test.
4.2. Deformation Mechanism of the Landslide. Besides the above blasting vibration monitoring test performed in the field, the field investigation was also carried out to observe the deformation of the landslide and understand its failure mechanism.

Our numerical and shaking table test results show that the factors triggering landslides could include bad geological conditions and improper blasting loading. This could be verified by our field investigation. For example, there are many weak mudstone intercalated layers with low strength in the south side of the first mining area of the open-pit mine. The weak intercalated layers have great rheology to cause their deformation to increase with time. Also, the weak layer is inclined, forming a natural potential slip surface, which is detrimental to the stability of the slope. If this instability occurs, the slope could slip along the weak mudstone layer. Our comprehensive study also shows that the influence of blasting vibration on the slope stability of the open-pit mine is also an important external factor of slope failure and landslide. As an example, Figure 16 presents a slide shear outlet of the landslide that occurred in the platform at the elevation of 912-948 m on August 22, 2011.

Different from traditional landslides, the landslide in this study presents several unique deformation and failure characteristics during the deformation evolution process, which are highlighted in the following three aspects. The 


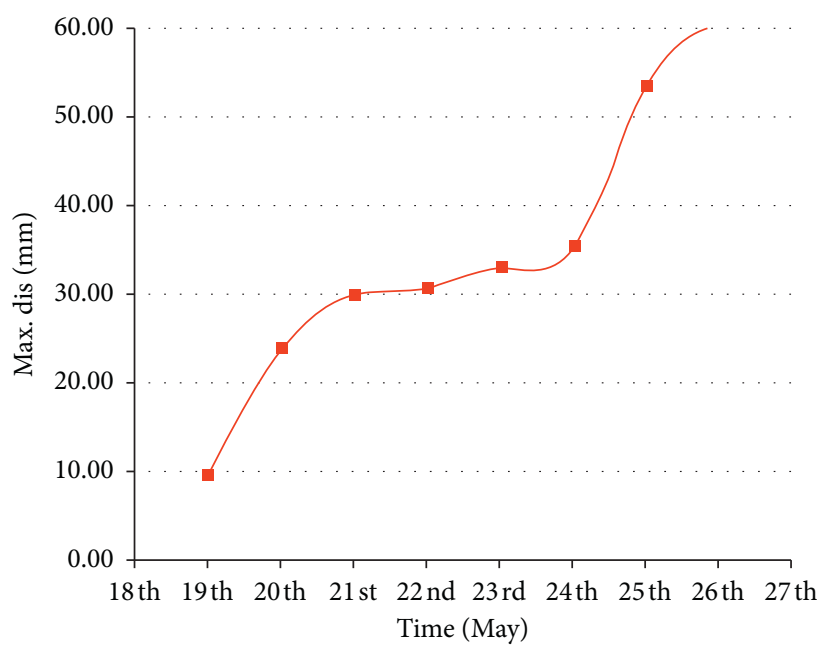

(a)

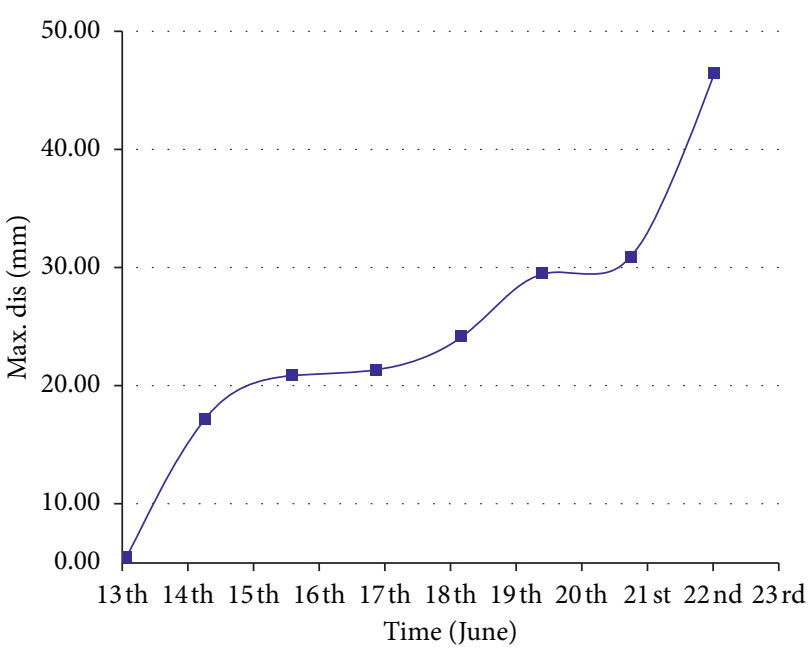

(b)

FIGURE 14: Variations of slope displacement during blasting.

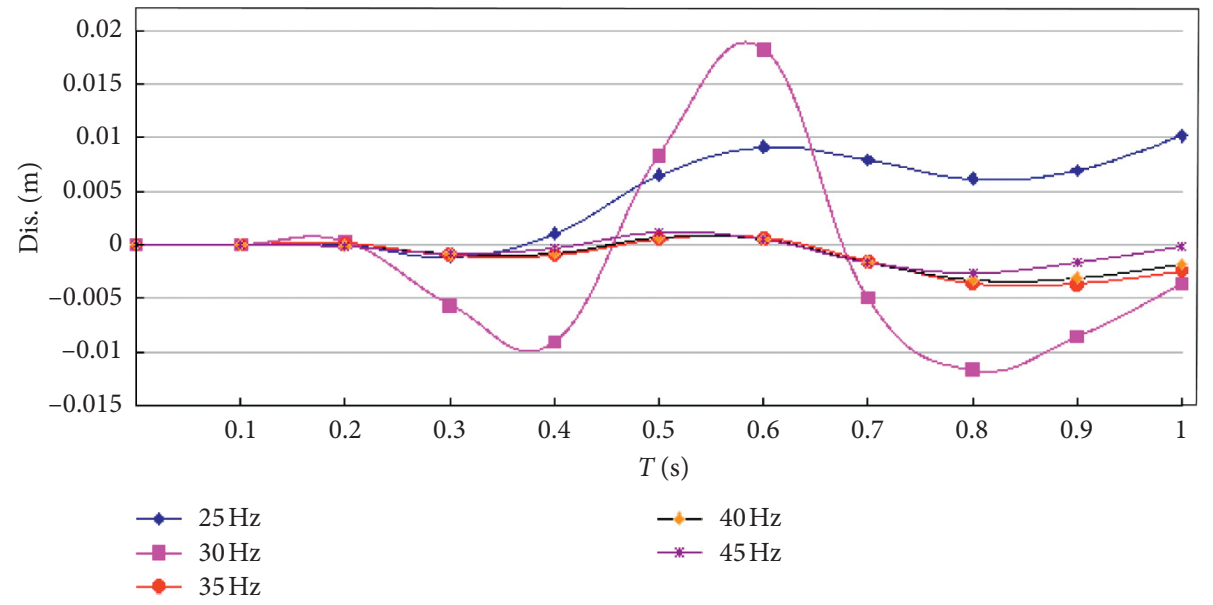

FIgURE 15: Displacement curves monitored at a certain point under blasting action.

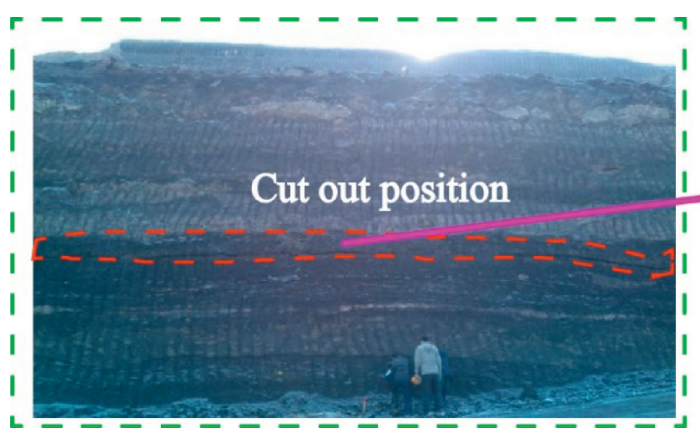

(a)

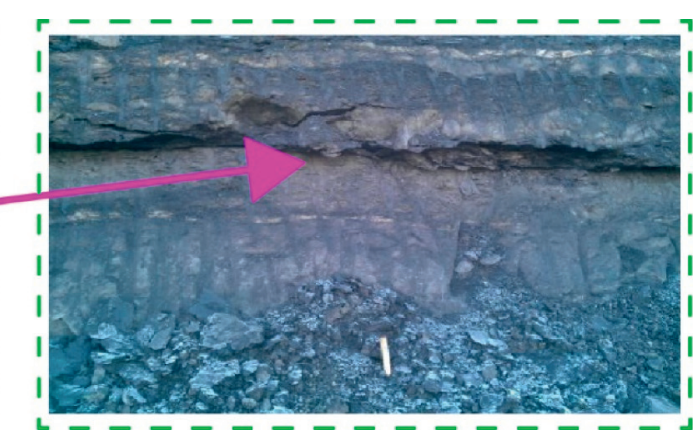

(b)

FIGURE 16: Shear deformation of the slope. (a) Slide shear outlet. (b) Locally enlarged view.

slope deformation duration is long, and its deformation rate is large. Although a series of landslides have occurred since 2011, the slope has been still in a state of constant deformation. The monitoring points between fracture zones have obvious migration at the beginning, and the deformation time has been as long as half a year; particularly, the cumulative displacement can reach tens of meters. The maximum deformation rate is always maintained at more than 


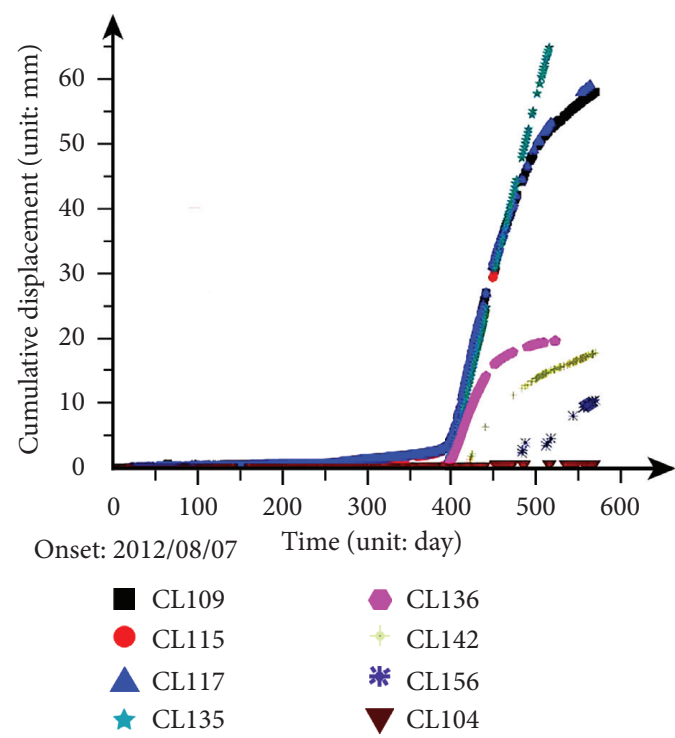

(a)

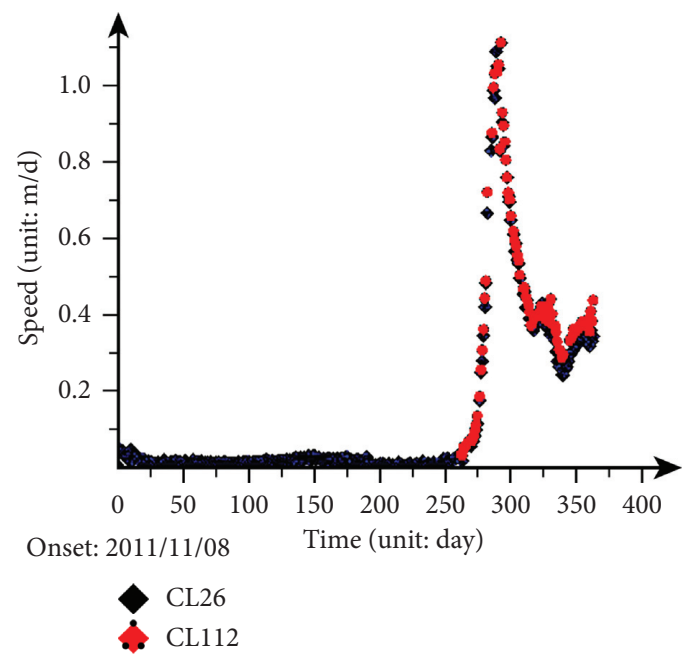

(b)

FIgURE 17: Monitoring data of the points with time. (a) Cumulative displacement. (b) Velocity.

tens of millimeters per day, and the rate during the severe deformation period can reach several meters per day. For example, the maximum deformation rate at CL26 and CL112 monitoring points can reach $1.08 \mathrm{~m}$ per day. The landslide has a long time, high rate of deformation, and evolution process, which is not the traditional landslide, as shown in Figure 17.

The failure mode of the landslide is the progressive and ulcerated sliding failure. The landslide began to damage near the F68 fault (Figures 18 and 19), and two arc-shaped fracture zones were successively formed, as shown in Figure 19. The failure area of the slope extends outwards step by step, presenting a gradual and ulcerated failure mode. According to the displacement monitoring curves (Figure 17), there are two groups of measuring points, including near fracture belt points (CL109, CL115, CL117, and CL135) and remote points (CL136, CL142, CL156, and CL104). The obvious difference between the displacement and velocity of the two groups of monitoring points can be found. Therefore, although these two groups of points are in the deformation zone, they cannot slide along a certain slip surface as a whole, but they just present multistage ulceration sliding deformation. The failure mode of the landslide is very different from the traditional slide failure mode of traction or push-back.

The deformation of the landslide is characterized by near-horizontal creep slip of the loose slide. During the deformation and failure process of the landslide, in the hanging wall area of the F68 fault below the elevation of $924 \mathrm{~m}$, loose slides constantly appear on the slope and eventually form a large area of loose slides accumulation area (see Figures 18 and 20). The gradient of the loose sliding body is similar to the horizontal level, but the sliding body is still able to move northward continuously, causing the exposed coal area at the bottom of the pit to be covered by the sliding body, which is in a wavy shape, as shown in the elliptic region in Figures 20(a) and 20(b). In addition, in November 2011 and October 2012, the slope foot pressing measures were implemented in the flat plate area at an elevation of $936 \mathrm{~m}$ and $924 \mathrm{~m}$, respectively, which not only failed to achieve east-west closure but also led to a large number of foot material migration to the depth of the slope (Figure 20). The movement of nearhorizontal loose slide and presser foot material is very different from the deformation and failure of the traditional landslide.

\section{Discussion}

The dynamic response characteristics of a coal rock slope in the open-pit mine were studied by numerical simulations, model tests, and field monitoring. The numerical simulation is used to study the wave propagation characteristics in the coal rock slope under the action of the blasting wave, and the influence of the weak intercalation on the wave propagation characteristics in the slope is also analyzed. It is difficult to analyze the wave characteristics of the slope in shaking table tests and field monitoring tests. However, the numerical simulation adopts the finite element method, which belongs to the study of dynamic response characteristics in the elastic domain of small deformation, and does not involve the study of the process of large deformation failure, deformation response characteristics, or failure modes. Hence, the shaking table test was used for further analysis. The purpose of the shaking table test is to study the deformation characteristics, failure process, and failure mode of the slope under the blasting wave and to explore the influence of blasting waves with different vibration frequencies on the dynamic deformation response of the slope. Moreover, the conclusion of the shaking table test is further verified by field monitoring.

Additionally, our comprehensive study shows that the natural frequency of the coal slope in this case study is $35 \mathrm{~Hz}$, indicating that the slope's natural frequency can be 


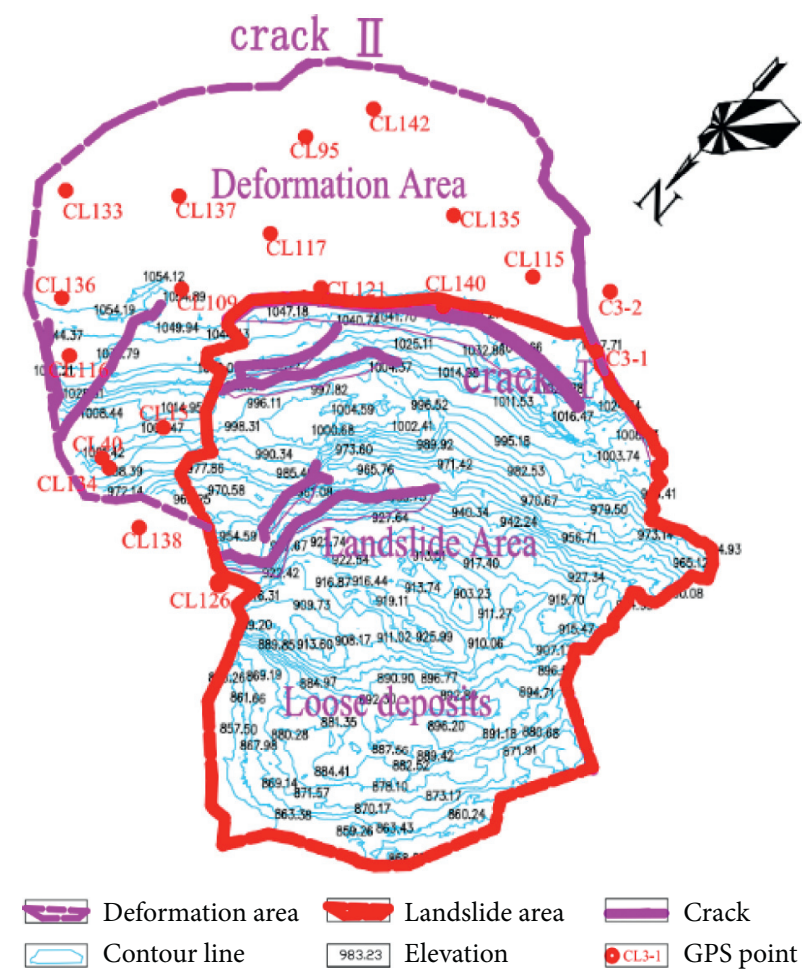

FIGURE 18: Distribution of monitoring points.

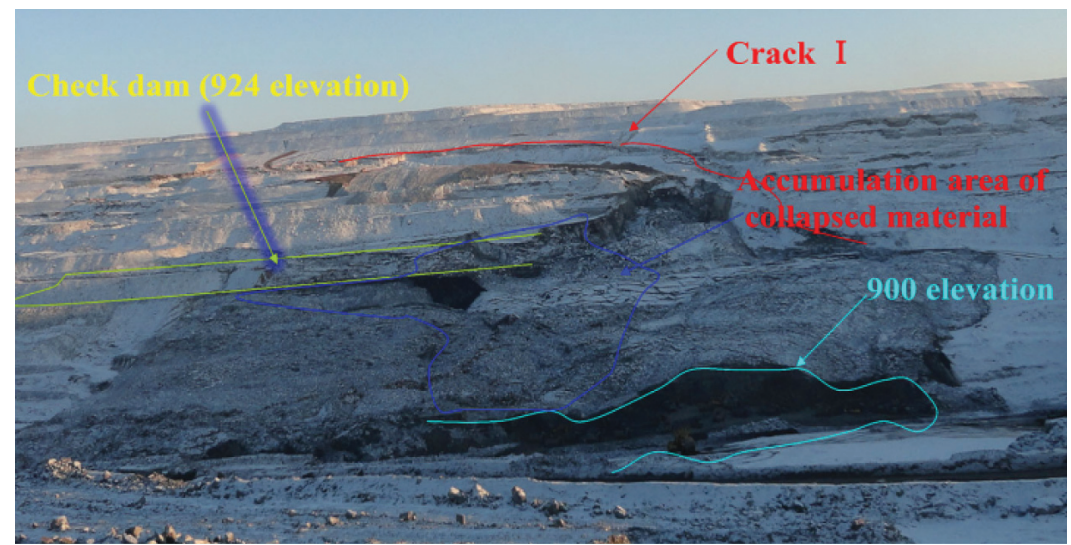

FIgURE 19: Overall outline of the landslide at the end of 2012.

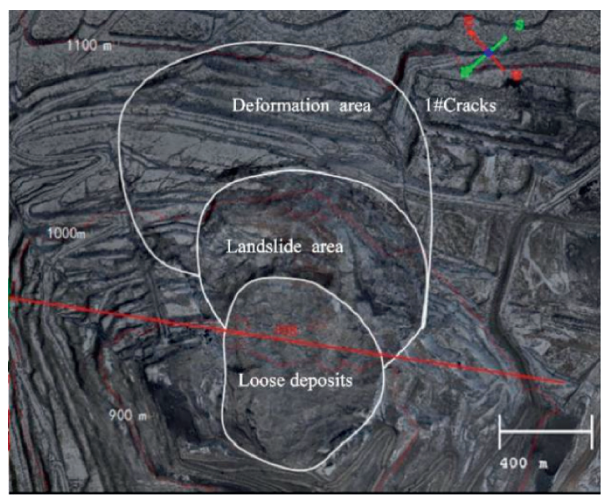

(a)

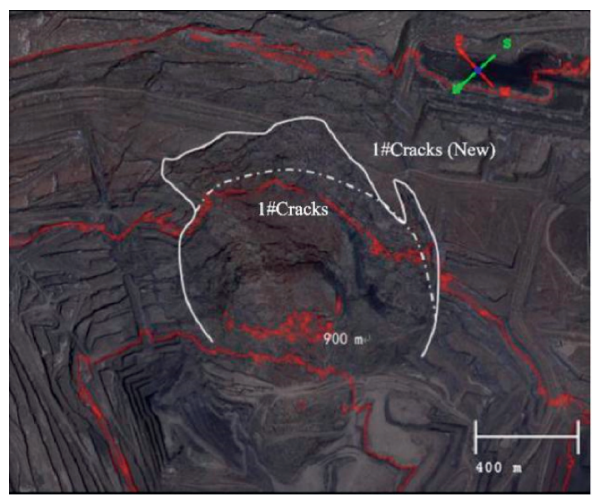

(b)

Figure 20: Continued. 


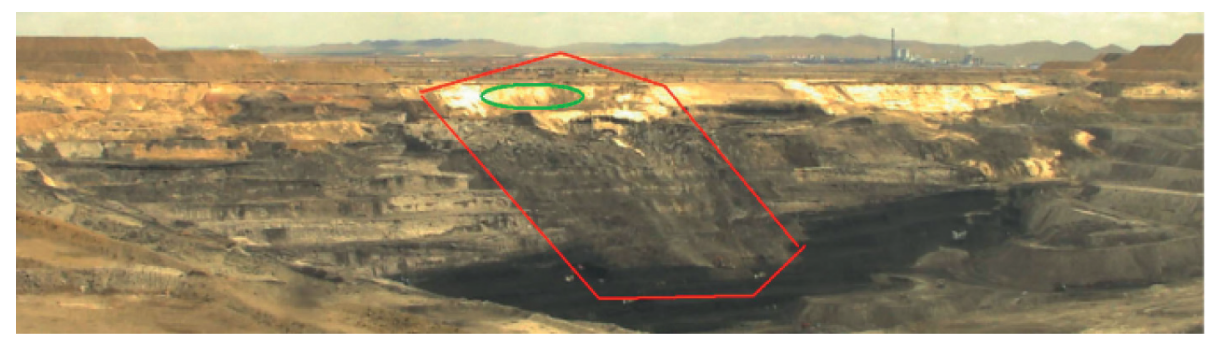

(c)

Figure 20: Aerial view of the landslide. (a) November 14, 2013. (b) February 15, 2014. (c) February 27, 2014 and April $26,2014$.

estimated by monitoring the maximum slope deformation when the slope is under blasting vibration with a series of frequencies. This procedure could thus be potentially used in the field to identify the natural frequency of coal slopes. Compared to the slope with homogeneous materials, the slope with weak intercalated layers has significant dynamic behaviors because the weak layers weaken the blasting wave propagation in the rock mass. The different mechanical properties of weak interlayer and the bulk slope zone induce a huge attenuation and interaction of blasting waves at the interface zone, as shown in Figure 9. However, the shaking table test and field investigations show that the weak intercalated layer could be the location where cracks initiate. This could be because the weak properties of the interlayer fail to resist large blasting wave energy. Further dynamic loading would trigger the propagation of cracks, causing the tensile shear failure along the sliding surface. Therefore, it is of great importance to identify the location, dimension, and structural properties of weak intercalated layers before the mining operation in the field. Studies such as [47] have been performed in this research topic.

Blasting loads are investigated in our study to benefit the engineering practice of underground mining or open-pit mining. While the dynamic failure modes and mechanisms of coal slopes are also paramount to its aseismic design, future studies could focus on the seismic response and deformation mechanism of coal slopes with weak intercalated layers under a strong earthquake.

\section{Conclusions}

Numerical methods, shaking table tests, and field tests were performed to study the dynamic response characteristics of a coal rock slope with weak interlayers under blasting loads. The following conclusions can be made:

(1) The weak interlayer has a damping effect on the propagation of blasting waves in the slope. The analyses of equivalent stress show that weak interlayer effectively improves the stress state of the slope under blasting loads, and the weak interlayer makes the slope easier to produce creep deformation.

(2) The shaking table test and field monitoring test results identify the natural frequency of the slope to be approximately $35 \mathrm{~Hz}$. When the vibration frequency of the blasting wave is $35 \mathrm{~Hz}$, the sliding body will slide along the weak bedding layer. The slope's natural frequency can be potentially determined by monitoring the maximum slope deformation when the slope is under blasting vibration with a series of frequencies.

(3) The specific deformation and failure process of the coal slope is shown as follows: first of all, cracks were formed in weak interlayers by blasting vibration, and the cracks expanded to form shear zones, which then led to vertical tension cracks on the slope crest. With the increase of vibration load, the cracks gradually penetrated and formed a sliding surface composed of tension and shear. The slip surface is formed by the combination of the shear slip surface of the weak bedding interlayer and the tension crack generated by the acceleration amplification at the top of the slope.

(4) Slope dynamic deformation is negatively correlated with the distance of the blasting source. The farther the distance from the blasting source is, the less the displacement, PGA, and PGD of the slope gradually decrease

(5) Future studies could focus on the seismic response and deformation mechanism of coal slopes with weak intercalated layers or other complex geological structures under a strong earthquake.

\section{Data Availability}

The data used to support the findings of this study are available from the corresponding author upon request.

\section{Conflicts of Interest}

The authors declare that there are no conflicts of interest regarding the publication of this paper.

\section{Acknowledgments}

This work was supported by the National Natural Science Foundation of China (Grant no. 51974144) and the Shuimu Tsinghua Scholar Program (2019SM058).

\section{References}

[1] L. J. Dong, X. L. Lei, and C. P. Lu, "Shock and vibration in deep mining science," Shock and Vibration, vol. 2019, Article ID 5209834, 3 pages, 2019. 
[2] L. Han, J. S. Shu, Q. X. Cai, H. W. Jing, and H. Tian, "Mechanical characteristics of dip basement effects on dump stability in the Shengli open pit mine in inner Mongolia, China," Arabian Journal of Geosciences, vol. 9, no. 20, Article ID 750, 2016.

[3] E. Bakhtavar, "The practicable combination of open pit with underground mining methods-a decade's experience," in Proceedings of 24th International Mining Congress and Exhibition of Turkey (IMCET), pp. 704-709, Antalya, Turkey, April 2015.

[4] V. Kutuev and S. Zharikov, "Restrictions on seismic impact of blast in the open-pit border zone at the open-pit and combined mining," E3S Web of Conferences, vol. 129, Article ID 01001, 2019.

[5] H. Y. Cheng, A. X. Wu, B. Han, H. Li, and C. L. Hou, "Stability of safety pillars in opencast-underground combined mining," Journal of Central South University (Science and Technology), vol. 47, no. 9, pp. 3183-3192, 2016.

[6] H. Tian and Z. X. Wang, "Disturbance behavior of open-pit mine on environment and its control technology," Journal of China Coal Society, vol. 43, no. 9, pp. 2416-2421, 2018, in Chinese.

[7] S. V. Tsirel, B. Y. Zuev, and A. A. Pavlovich, "The influence of earthquakes on open-pit slope stability," International Journal of Geosciences, vol. 3, no. 4, pp. 799-808, 2012.

[8] Z. H. Zhou, Z. H. Chen, J. M. Wang, L. F. Zhang, and G. Q. Ning, "Catastrophe analysis of open-pit slope stability under blasting," Rock and Soil Mechanics, vol. 41, no. 3, pp. 1-10, 2020, in Chinese.

[9] D. Q. Song, J. D. Chen, and J. H. Cai, "Deformation monitoring of rock slope with weak bedding structural plane subject to tunnel excavation," Arabian Journal of Geosciences, vol. 11, no. 11, p. 251, 2018.

[10] B. Azarfar, S. Ahmadvand, J. Sattarvand, and B. Abbasi, "Stability analysis of rock structure in large slopes and openpit mine: numerical and experimental fault modeling," Rock Mechanics and Rock Engineering, vol. 52, no. 12, pp. 48894905, 2019.

[11] M. Amini and A. Ardestani, "Stability analysis of the northeastern slope of Daralou copper open pit mine against a secondary toppling failure," Engineering Geology, vol. 249, no. 1, pp. 89-101, 2019.

[12] D. Song, A. Che, R. Zhu, and X. Ge, "Dynamic response characteristics of a rock slope with discontinuous joints under the combined action of earthquakes and rapid water drawdown," Landslides, vol. 15, no. 6, pp. 1109-1125, 2018.

[13] M. Babaeian, M. Ataei, F. Sereshki, F. Sotoudeh, and S. Mohammadi, "A new framework for evaluation of rock fragmentation in open pit mines," Journal of Rock Mechanics and Geotechnical Engineering, vol. 11, no. 2, pp. 325-336, 2019.

[14] C. Obregon and H. Mitri, "Probabilistic approach for open pit bench slope stability analysis-a mine case study," International Journal of Mining Science and Technology, vol. 29, no. 4, pp. 629-640, 2019.

[15] D. Whittle, M. Brazil, P. A. Grossman, J. H. Rubinstein, and D. A. Thomas, "Combined optimisation of an open-pit mine outline and the transition depth to underground mining," European Journal of Operational Research, vol. 268, no. 2, pp. 624-634, 2018.

[16] L. Ma, K. M. Li, X. H. Ding, H. G. Peng, and S. S. Xiao, "Development and application of blast casting technique in large-scale surface mines: a case study of Heidaigou surface coal mine in China," Shock and Vibration, vol. 2016, Article ID 8496742, 11 pages, 2016.

[17] Z. Bednarczyk, "Slope stability analysis for the design of a new lignite open-pit mine," Procedia Engineering, vol. 191, pp. 51-58, 2017.

[18] Z. Chen, D. Song, C. Hu, and Y. Ke, "The September 16, 2017, Linjiabang landslide in Wanyuan County, China: preliminary investigation and emergency mitigation," Landslides, vol. 17, no. 1, pp. 191-204, 2020.

[19] S. Xu, F. T. Suorineni, L. An, Y. H. Li, and C. Y. Jin, "Use of an artificial crown pillar in transition from open pit to underground mining," International Journal of Rock Mechanics and Mining Sciences, vol. 117, no. 5, pp. 118-131, 2019.

[20] S. N. Wang, W. Y. Xu, and J. Y. Liu, "Stability and failure mechanism analyses of the Zhenggang landslide in southwestern China," Advances in Civil Engineering, vol. 2018, Article ID 6128401, 16 pages, 2018.

[21] A. Azhari and U. Ozbay, "Investigating the effect of earthquakes on open pit mine slopes," International Journal of Rock Mechanics and Mining Sciences, vol. 100, no. 12, pp. 218-228, 2017.

[22] X. Y. Hou, S. L. Liu, S. Zhao, S. Dong, Y. Sun, and R. Beazley, "The alpine meadow around the mining areas on the QinghaiTibetan plateau will degenerate as a result of the change of dominant species under the disturbance of open-pit mining," Environmental Pollution, vol. 254, Article ID 113111, 2019.

[23] L. Espitia-Pérez, M. Arteaga-Pertuz, J. S. Soto et al., "Geospatial analysis of residential proximity to open-pit coal mining areas in relation to micronuclei frequency, particulate matter concentration, and elemental enrichment factors," Chemosphere, vol. 206, pp. 203-216, 2018.

[24] B. King, M. Goycoolea, and A. Newman, "Optimizing the open pit-to-underground mining transition," European Journal of Operational Research, vol. 257, no. 1, pp. 297-309, 2017.

[25] Z. Che and H. Yang, "Application of open-pit and underground mining technology for residual coal of end slopes," Mining Science and Technology (China), vol. 20, no. 2, pp. 266-270, 2010.

[26] N. A. C. Londoño, H. I. Londoño, and N. McIntyre, "Comparing the environmental sustainability of two gold production methods using integrated Emergy and Life Cycle Assessment," Ecological Indicators, vol. 107, no. 12, Article ID 105600, 2019.

[27] S. S. Kang, B. A. Jang, C. W. Kang, Y. Obara, and J. M. Kim, "Rock stress measurements and the state of stress at an openpit limestone mine in Japan," Engineering Geology, vol. 67, no. 1-2, pp. 201-217, 2002.

[28] Y. Obara, N. Nakamura, S. S. Kang, and K. Kaneko, "Measurement of local stress and estimation of regional stress associated with stability assessment of an open-pit rock slope," International Journal of Rock Mechanics and Mining Sciences, vol. 37, no. 8, pp. 1211-1221, 2000.

[29] C. Romer and M. Ferentinou, "Numerical investigations of rock bridge effect on open pit slope stability," Journal of Rock Mechanics and Geotechnical Engineering, vol. 11, no. 6, pp. 1184-1200, 2019.

[30] J. W. Zhan, Q. Wang, W. Zhang, Y. Shangguan, S. Song, and J. Chan, "Soil-engineering properties and failure mechanisms of shallow landslides in soft-rock materials," CATENA, vol. 181, no. 10, Article ID 104093, 2019.

[31] R. Halatchev and D. Gabeva, "Probabilistic analysis of seismic impact on open pit slope stability," International Journal of 
Mining, Reclamation and Environment, vol. 31, no. 3, pp. 167-186, 2017.

[32] N. Ceryan, A. Kesimal, and S. Ceryan, Probabilistic Analysis Applied to Rock Slope Stability: A Case Study from Northeast Turkey, Integrating Disaster Science and Management, pp. 221-261, Elsevier, Istanbul, Turkey, 2018.

[33] I. E. Zevgolis, A. V. Deliveris, and N. C. Koukouzas, "Probabilistic design optimization and simplified geotechnical risk analysis for large open pit excavations," Computers and Geotechnics, vol. 103, pp. 153-164, 2018.

[34] J. G. Du, G. W. Wang, and L. H. Jia, "In situ major and trace element compositions of apatites from Luanchuan orecluster: implications for porphyry mo mineralization," Ore Geology Reviews, vol. 115, Article ID 103174, 2019.

[35] L. Y. Wang, Y. Xu, Y. Li, and Y. D. Zhao, "Voxel segmentation-based 3D building detection algorithm for airborne LIDAR data," PLoS One, vol. 13, no. 12, pp. 1-26, 2018.

[36] Y. Chen, J. Zuo, D. Liu, and Z. Wang, "Deformation failure characteristics of coal-rock combined body under uniaxial compression: experimental and numerical investigations," Bulletin of Engineering Geology and the Environment, vol. 78, no. 5 , pp. 3449-3464, 2019.

[37] Ö. Bozkaya, G. Bozkaya, H. Yılmaz, D. Hozatlığluc, and D. A. Banks, "The origin, age and duration of hydrothermal alteration associated with iron skarn mineralization determined from clay/phyllosilicate minerals, Bizmisen-Erzincan, East-Central Turkey," Ore Geology Reviews, vol. 115, Article ID 103179, 2019.

[38] B. Liu, H. Li, Q. H. Wu, H. Kong, and X. S. Xi, "Double-vein (ore-bearing vs. ore-free) structures in the Xitian ore field, South China: implications for fluid evolution and mineral exploration," Ore Geology Reviews, vol. 115, Article ID 103181, 2019.

[39] P. W. Shen, H. M. Tang, Y. B. Ning, and D. Xia, “A damage mechanics based on the constitutive model for strain-softening rocks," Engineering Fracture Mechanics, vol. 216, Article ID 106521, 2019.

[40] D. Song, A. Che, R. Zhu, and X. Ge, "Natural frequency characteristics of rock masses containing a complex geological structure and their effects on the dynamic stability of slopes," Rock Mechanics and Rock Engineering, vol. 52, no. 11, pp. 4457-4473, 2019.

[41] D. Luo, G. S. Su, and G. L. Zhang, "True-triaxial experimental study on mechanical behaviours and acoustic emission characteristics of dynamically induced rock failure," Rock Mechanics and Rock Engineering, vol. 53, no. 3, pp. 1205-1223, 2019.

[42] Q. H. Wu, X. B. Li, L. Weng, Q. Li, Y. Zhu, and R. Luo, "Experimental investigation of the dynamic response of prestressed rockbolt by using an SHPB-based rockbolt test system," Tunnelling and Underground Space Technology, vol. 93, no. 11, Article ID 103088, 2019.

[43] D. Q. Song, Z. Chen, C. Hu, Y. T. Ke, and W. Nie, "Numerical study on seismic response of a rock slope with discontinuities based on the time-frequency joint analysis method," Soil Dynamics and Earthquake Engineering, vol. 133, Article ID 106112, 2020.

[44] N. Jiang, C. Zhou, S. Lu, and Z. Zhang, "Propagation and prediction of blasting vibration on slope in an open pit during underground mining," Tunnelling and Underground Space Technology, vol. 70, no. 11, pp. 409-421, 2017.

[45] Y. Ning, G. Zhang, H. Tang, W. Shen, and P. Shen, "Process analysis of toppling failure on anti-dip rock slopes under seismic load in southwest China," Rock Mechanics and Rock Engineering, vol. 52, no. 11, pp. 4439-4455, 2019.

[46] D. Song, A. Che, Z. Chen, and X. Ge, "Seismic stability of a rock slope with discontinuities under rapid water drawdown and earthquakes in large-scale shaking table tests," Engineering Geology, vol. 245, pp. 153-168, 2018.

[47] G. Fan, J.-J. Zhang, X. Fu, and L.-R. Zhou, "Dynamic failure mode and energy-based identification method for a counterbedding rock slope with weak intercalated layers," Journal of Mountain Science, vol. 13, no. 12, pp. 2111-2123, 2016.

[48] H. Krawinkler and P. D. Moncarz, "Theory and application of experimental model analysis in earthquake engineering," Technical report No. 82, NASA STI/RECON, Standford, CA, USA, 1981.

[49] L. R. Herrman and F. E. Peterson, "A numerical procedure for viscoelastic stress analysis," in Proceedings of the ICRPG Mechanical Behavior Working Group, Orlando, FL, USA, 1968. 